\title{
1 Indirect versus Direct Effects of Freshwater Browning on 2 Larval Fish Foraging
}

3

4 Dina M. Leech, Troy L. Clift, Jessica L. Littlefield, Nicholas R. Ravagli, and Jacob E.

5 Spain

6

7 Department of Biological and Environmental Sciences

8 Longwood University Farmville, VA 23901

10 Corresponding Author: Dina M. Leech, Department of Biological and Environmental

11 Sciences, 201 High Street, Longwood University, Farmville, VA, 23909; Office \#: 434.395.4966;

12 Email: leechdm@longwood.edu

13

14 Keywords: brownification, fish larvae, foraging, predation, zooplankton

15

Running Title: Browning and larval fish foraging

17

18

19

20

21

22

23

24

25

26

27

28

29

30

31

32

33

34

35

36

37 


\section{Browning and larval fish foraging -- 2}

\section{ABSTRACT}

39

40

41

42 juveniles and adults; however, the larval stage represents a 'critical period' in fish development.

43 We investigated the indirect versus direct effects of browning on zooplankton-larval fish

44 interactions by altering water color with SuperHume (absorbance at $440 \mathrm{~nm}=1.6-10.8 \mathrm{~m}^{-1}$ ).

45 Phytoplankton and zooplankton densities were monitored across experimental tanks in the

46 laboratory for one month leading up to fish spawning. Larval largemouth bass were then

47 introduced to assess indirect effects on fish feeding rates and growth. Direct effects on foraging

48 of largemouth bass and bluegill were determined with separate short-term feeding

49 experiments. Browning did not directly alter the ability of larval fish to capture prey. However,

50 significant indirect effects on larval fish foraging, growth, and survival were observed as

51 phytoplankton and zooplankton decreased with increased browning. Our data suggest lake

52 browning will reduce energy transfer to larval fish due to a reduction in prey availability but not

53 visual foraging.

54

55

56

57

58

59

60 


\section{Introduction}

62

63

64

65

66

67

68

69

70

71

72

73

74

75

76

77

78

79

80

81

82
In recent decades, many freshwater and coastal ecosystems in the Northern Hemisphere have become browner in color due to an increased export of chromophoric dissolved organic matter (cDOM) from the terrestrial watershed (Monteith et al. 2007;

Erlandsson et al. 2008; Haaland et al. 2010; Solomon et al. 2015). The mechanisms underlying this 'browning' are currently debated and include changes in climate, hydrology, and land use, reduced atmospheric acid deposition, and increased inputs of dissolved iron (Freeman et al. 2001; Monteith et al. 2007; Erlandsson et al. 2008; Kritzberg and Ekström 2012). Whatever the mechanism, this phenomenon has far reaching ecological consequences for the structure and function of aquatic ecosystems, including energy flow.

One concern is the effect of browning on the underwater light environment. As waters become browner in color, the quantity of light in the water column is reduced, resulting in a shallower euphotic zone (Bukaveckas and Robbins-Forbes 2000; Einem and Graneli 2010). In addition, shorter wavelength ultraviolet and visible radiation are more readily absorbed by cDOM compared to longer wavelengths (Morris et al. 1995; Wetzel 2001). Consequently, the light environment shifts to the red portion of the visible spectrum. These alterations in the quantity and quality of light have the potential to affect zooplankton-fish interactions-indirectly through reduced energy transfer up the food chain and directly through reduced foraging efficiency.

While recent studies have shown that the initial browning of low productive systems can stimulate primary production (Ask et al. 2012; Seekell et al. 2015; Williamson et al. 2015), excessive browning of fresh waters can reduce rates of photosynthesis due to competition for 
84 photons (Kirk 1994). CDOM has been reported to sequester 10 times more photons within the

85 visible spectrum (400 - $700 \mathrm{~nm}$ ) compared to photosynthetic pigments (Thrane et al. 2014). As

86 a consequence, areal primary production often decreases with increased water color (Jones

87 1992; Carpenter et al. 1998; Ask et al. 2009; Karlsson et al. 2009; Thrane et al. 2014), and

88 pelagic primary production typically exceeds benthic primary production (Vasconcelos et al.

89 2018; Vasconcelos et al. 2019). Phytoplankton community composition can also shift to

90 predominantly cyanobacteria, which are generally less nutritious or inedible to zooplankton

91 (Ekvall et al. 2013; Robidoux et al. 2015). Overall, aquatic ecosystems often become net

92 heterotrophic with increased browning as bacterial production exceeds primary production

93 (Cole et al. 1994; Ask et al. 2012).

Reductions in the quantity and quality of basal resources then 'cascade up' the grazer

95 food chain to influence zooplankton and fish. For example, Robidoux et al. (2015) observed decreases in crustacean zooplankton biomass and density with increased water color while

97 Craig et al. (2017) found that bluegill in lakes of increasing color were smaller in size and had

98 lower fecundity compared to those living in lakes with less color. Taipale et al. (2018) noted

99 that zooplankton and fish had poorer nutritional quality in browner systems because the

100 phytoplankton on which they fed had lower concentrations of essential fatty acids, proteins,

101 lipids, and carbohydrates. Combined, these results suggest that freshwater browning indirectly

102 alters energy flow to higher trophic levels.

103 Trophodynamics between larval fish and zooplankton are particularly important as the

104 larval stage represents a critical phase in fish development that ultimately affects population

105 growth and biomass (Fuiman and Werner 2002; Karlsson et al. 2009; Karlsson et al. 2015). 
106 Generally, in temperate climates, increased primary production in the late spring/early summer

107 leads to increased zooplankton production. Shortly thereafter, many fish species begin to

108 spawn, matching larval fish hatching with an abundance of zooplankton prey (Mills et al. 1989;

109 Mehner and Thiel 1999; Hansson et al. 2007). However, as fresh waters continue to brown and

110 energy flow to zooplankton is reduced, fish larvae may compete for fewer zooplankton prey.

111 Freshwater browning may also directly affect fish foraging behavior by altering the light

112 environment to which fish are adapted. Many fish are visually orienting predators, depending

113 on the quantity (i.e. intensity) and quality (i.e. spectra) of underwater light to locate and

114 capture prey (Guthrie and Muntz 1993; Leech and Johnsen 2009). Results from studies

115 investigating the direct effects of browning on fish foraging are varied, ranging from no effect

116 to enhanced effects (e.g. Stasko et al. 2012; Jönsson et al. 2013; Weidel et al. 2017). However,

117 this research has focused on juvenile and adult life history stages, with no knowledge of the

118 effect of browning on fish larvae.

119 Foraging in early life history stages may be particularly affected by freshwater browning

120 due the rapid attenuation of shorter wavelength light. Over evolutionary time, the visual

121 system of fishes spectrally tunes to the intensity and wavelengths of light present in their

122 environment, varying with age and behavior (Douglas and Djamgoz 1990). Larval fish spend

123 most of their time foraging in the top few meters of the epilimnion, and many species have

124 been shown to possess UV photoreceptors during only their early stages of development

125 (reviewed in Leech and Johnsen 2009). Thus, fish larvae may rely on short-wavelength

126 ultraviolet and blue radiation to forage (Leech and Johnsen 2009 and references therein).

127 Alternatively, as light levels decline, fish larvae may rely on other sensory mechanisms to 
128 forage, such as olfactory cues or mechanoreception, as demonstrated in marine fish larvae and

129 zebrafish (Jones and Janssen 1992; Cobcroft and Pankhurst, 2003; Sampson et al. 2013; Carillo 130 and McHenry 2016).

131 Here, we use laboratory experiments to assess the indirect versus direct effects of

132 browning on larval fish foraging at the time of hatching (i.e., late spring/early summer in central

133 Virginia, USA). Based on the primary literature, we hypothesized that increased browning will

134 reduce phytoplankton biomass, leading to a reduction in zooplankton abundance, and

135 consequently larval fish foraging efficiency, growth, and survival during an early, critical stage in

136 development. We then used the same laboratory set up to examine the direct effects of

137 browning on fish feeding rate and prey selectivity when given equal zooplankton prey,

138 hypothesizing that fish larvae will consume less prey as water color increases due to a reduction

139 in light availability for foraging.

140 Methods

141 Indirect Effects of Browning

142 Laboratory experiments were conducted in twelve $20 \mathrm{~L}$ glass aquaria assembled on

143 three shelves with four tanks per shelf. The entire shelving unit, including individual shelves,

144 was covered in black plastic with additional black plastic placed in between each tank.

145 Experimental tanks were arranged in a randomized block design, with at least one tank from

146 each treatment on each shelf. Nine tanks were filled with $17 \mathrm{~L}$ of artificial lake water made from

147 the COMBO medium recipe, which provides macro- and micronutrients in relatively high

148 concentrations to support growth (Kilham et al. 1998). SuperHume, a commercially available

149 source of humic acid, was then added to the tanks at varying concentrations to adjust the 
150 brown color of the water. Three tanks received $7 \mu \mathrm{g} / \mathrm{L}$ of SuperHume to serve as a light brown

151 treatment (water color measured as absorbance at $440 \mathrm{~nm}\left(\mathrm{a}_{440}\right)=1.6 \mathrm{~m}^{-1}$ ), three tanks

152 received $33 \mu \mathrm{g} / \mathrm{L}$ to serve as a moderate brown treatment $\left(\mathrm{a}_{440}=5.7 \mathrm{~m}^{-1}\right)$, and three tanks

153 received $66 \mu \mathrm{g} / \mathrm{L}$ to serve as a dark brown treatment $\left(\mathrm{a}_{440}=10.8 \mathrm{~m}^{-1}\right)$. While SuperHume adds

154 carbon to the system, it does not add nutrients. Thus, despite differences in water color, and

155 consequently light transparency, our treatments had similar nutrient concentrations. We

156 adjusted the $\mathrm{pH}$ of all tanks to $\sim 7$ with approximately $2 \mu \mathrm{L}$ of $2 \mathrm{~N} \mathrm{HCl}$.

157 Although the experimental use of SuperHume has been previous tested (Lennon et al.

158 2013; Övergaard 2019), some have cited toxicity concerns for zooplankton (Robidoux et al.

159 2015). We therefore filled the remaining three tanks with $17 \mathrm{~L}$ of lake water from Sandy River

160 Reservoir, Farmville, VA $\left(\mathrm{a}_{440}=1.5 \mathrm{~m}^{-1}\right)$ to serve as a comparison with our light brown

161 SuperHume treatment. Lake water was passed through a GF/F filter to remove bacterio-,

162 phyto-, and zooplankton, as best as possible. Sandy River Reservoir water was not used as the

163 base water for all browning treatments because of the logistics of transporting and filtering the

164 necessary large volume of water needed for the experiment.

165 Light was provided by 1.2 m long grow lamps containing two Lumichrome ${ }^{\circledR}$ Full

166 Spectrum Plus fluorescent, $32 \mathrm{~W}$ bulbs suspended approximately $10 \mathrm{~cm}$ above the water surface

167 of the tanks on each shelf and placed on a 14-hr light, 10-hr dark cycle. While lamps cannot

168 exactly reproduce the solar spectrum, these specific bulbs were selected based on their broad

169 coverage of the ultraviolet and visible spectra. An Ocean Optics Red Tide USB650 UV

170 spectrophotometer was used to measure the light spectrum, based on photon counts, from 250

171 to $800 \mathrm{~nm}$ in each treatment (Figure 1). After the experiment had concluded, we acquired a 
172 LiCor LI-192 quantum sensor to estimate photosynthetically active radiation (PAR) across our

173 treatments. The sensor was placed in the center of the tank at a depth of $0.09 \mathrm{~m}$. PAR ranged

174 from approximately $15 \mu \mathrm{mol} \mathrm{m} \mathrm{m}^{-2} \mathrm{~s}^{-1}$ in the dark brown treatment, $22 \mu \mathrm{mol} \mathrm{m} \mathrm{m}^{-2} \mathrm{~s}^{-1}$ in the

175 moderate brown treatment, and $31-35 \mu \mathrm{mol} \mathrm{m} \mathrm{m}^{-2} \mathrm{~s}^{-1}$ in the lake water and light brown

176 treatments. These light levels are comparable to those experienced during crepuscular periods,

177 when larvae often actively forage (Keast and Welsh 1968; Leech and Johnsen 2009). They are

178 also representative of light levels experienced at midday in the summer between approximately

$179 \quad 1.0-2.5 \mathrm{~m}$ depth in local, natural systems (i.e. $1800 \mu \mathrm{mol} \mathrm{m} \mathrm{m}^{-2} \mathrm{~s}^{-1}$ surface irradiance, Figure

180 S1). All tanks stabilized to a room temperature of $22-23^{\circ} \mathrm{C}$ under both light and dark

181 conditions.

At the beginning of the experiment, each tank received a dense mixture of

183 phytoplankton containing equal parts of Ankistrodesmus sp., Chlorella sp., Scenedesmus sp.,

184 and Selenastrum sp., which resulted in an initial chlorophyll- $a$ concentration of approximately

$18510 \mu \mathrm{g} / \mathrm{L}$ in all tanks. Algae were purchased from Carolina Biological and cultured in COMBO

186 medium prior to the experiment. A mixed assemblage of zooplankton was then added to each

187 tank. Zooplankton were collected from Sandy River Reservoir the day before the experiment by

188 towing a $64 \mu \mathrm{m}$ mesh bongo net from 0 - $6 \mathrm{~m}$ several times. Prior to introduction, zooplankton

189 were concentrated into a single $4 \mathrm{~L}$ container, mixed, and then $50 \mathrm{~mL}$ aliquots were introduced

190 into each tank to provide a starting density of approximately 26 zooplankton per liter in each

191 tank. This initial relatively low density permitted observations of population growth over time

192 and reflected natural zooplankton concentrations in the early spring in local systems.

193 Proportionally, the zooplankton assemblage consisted of $80 \%$ copepods (mostly cyclopoids), 
194 15\% cladocerans (Daphnia sp. and Bosmina sp.), and 5\% rotifers (Keratella sp.). We removed all

195 Chaoborus before introducing the zooplankton to the tanks to minimize zooplankton mortality

196 due to predation.

197 Over the course of the next month, phytoplankton biomass and zooplankton abundance

198 were measured at 0, 3, 7, 14, 21 and 28 days. Before each sampling, tanks were gently mixed

199 with a broad, plastic spoon. For phytoplankton, two replicate $50 \mathrm{~mL}$ water samples were

200 removed from each tank and filtered through Whatman GF/F filters to measure chlorophyll-a

201 concentration as a proxy for phytoplankton biomass. Filters were placed in $90 \%$ acetone

202 overnight in the freezer and then chlorophyll- $a$ concentration was measured on a Shimadzu

203 Trilogy Fluorometer using the non-acidification module. Chlorophyll-a concentrations are

204 reported as the average of these two replicates. One hundred milliliters of DI water were added

205 to each tank to replace the $100 \mathrm{~mL}$ removed for chlorophyll-a analysis, keeping the volume at

$206 \sim 17 \mathrm{~L}$.

For zooplankton, $3 \mathrm{~L}$ of water from each tank was passed through a $64 \mu \mathrm{m}$ mesh cup,

208 and then the water was immediately returned to the tank to maintain a constant volume.

209 Zooplankton collected on the mesh were rinsed into a sample cup and preserved with $70 \%$

210 ethanol. Zooplankton were identified and enumerated under a dissecting microscope at 40x in

211 a Ward counting wheel. Zooplankton density (individuals per liter) was determined by counting

212 the total number of rotifers, copepods, and cladocerans in each sample collection and then

213 dividing by the total volume of water sampled (i.e. $3 \mathrm{~L}$ ).

Because bacteria can serve as an alternate food source for zooplankton, either directly

215 or through the microbial loop (Sanders and Porter 1990; Wylie and Currie 1991), we measured 
216 bacterial abundance at Days 0 and 28. Five milliliters of water were collected from each tank

217 with a serological pipet, placed in a sterile culture tube, and preserved with glutaraldehyde.

218 Samples were refrigerated until analysis. Bacterial abundance was determined by counting

219 DAPI stained cells under an epifluorescent microscope at a magnification of 100x, based on the

220 methods of Porter and Feig (1980). A minimum of 400 cells were counted per sample to

221 determine cell density per milliliter.

After 28 days, two larval largemouth bass (Micropterus salmonoides), 10-12 mm in

223 standard length (i.e. body length excluding tail), were introduced to each tank. Preliminary

224 experiments determined the fish behaved better in pairs compared to single introductions. We

225 chose to introduce the larvae after one month to simulate the timing of fish hatching in nature

226 following an increase in algae and zooplankton in late spring (Mills et al. 1989; Mehner and

227 Thiel 1999; Hansson et al. 2007). Because we were unable to successfully obtain fish larvae

228 from Sandy River Reservoir prior to the experiment, we used larvae from a local pond with

229 similar optical characteristics. Fish larvae were collected using light traps (Aquatic Instruments,

230 Inc., Hope, ID) anchored in the littoral zone of the pond overnight. Fish were immediately

231 transported back to the lab and housed for 24 hours without food. Fish collection and care

232 followed approved institutional animal care and use protocols.

Once introduced to the experimental tanks, the fish larvae were allowed to feed for 24

234 hours. After which, zooplankton were sampled as described above. This provided an estimate

235 of daily zooplankton consumption in each treatment, assuming that total zooplankton

236 consumed was represented by the difference in zooplankton density at the beginning and end

237 of fish feeding. We also assumed that the two fish in each tank fed equally, such that the 
238 difference in zooplankton density was divided by 2 to estimate daily consumption rates per fish

239 larva.

240 Fish were then allowed to feed in the tanks for another 5 days with survival monitored

241 daily. After which, fish larvae were euthanized in MS-222, and final measurements were taken

242 of their body length under a dissecting microscope to estimate growth. Because we could not

243 clearly distinguish the two fish in each tank, growth was estimated as the average size of the

244 two fish at the beginning versus the end of the experiment. A final collection was also made of

245 zooplankton density in the tanks. However, zooplankton abundance was too low in all the tanks

246 to make accurate counts.

247 Throughout the experiment, a YSI 600 XLM sonde was used to measure water

248 temperature, conductivity, $\mathrm{pH}$, and dissolved oxygen concentration in each tank. To monitor

249 potential changes in water color over time, a Shimadzu UV/Vis spectrophotometer was used to

250 measure absorbance at $440 \mathrm{~nm}$ of water filtered through a GF/F filter. Dissolved organic carbon

251 (DOC) concentration was also monitored during the experiment using GF/F filtrate. Samples

252 were run on a Shimadzu TOC-L analyzer.

253 Direct Effects of Browning

254 The same experimental setup was used to investigate direct effects of browning on fish

255 foraging efficiency. However, we did not use a lake water control. Light to dark brown water

256 color treatments consisted of four replicate tanks assembled in a randomized, block design on

257 the three shelves. After adding SuperHume to the tanks, we noted that water color ranged

258 from $\mathrm{a}_{440}=1.6$ to $13.1 \mathrm{~m}^{-1}$. In each tank, the $\mathrm{pH}$ was adjusted to approximately 7 , and the

259 water was allowed to equilibrate to room temperature $\left(22-23^{\circ} \mathrm{C}\right)$. A YSI $600 \mathrm{XLM}$ sonde was 
used to determine the water temperature, conductivity, dissolved oxygen concentration, and

$261 \mathrm{pH}$ of each tank prior to the beginning of each feeding experiment.

263 Reservoir. Fish larvae were starved for 24 hours prior to the experiment. For each experimental

264 tank, two larval fish ( 13 $\mathrm{mm}$ in length) were introduced and allowed to acclimate for a

265 minimum of 1 hour. After which, a known concentration of zooplankton prey (i.e. $~ 20$

266 zooplankton/L) was added, and the fish were allowed to feed for 30 minutes. We staggered the

267 introduction of the zooplankton every 10-15 minutes to allow time for disassembling each tank

268 at the end of the timed feeding trial. The zooplankton community consisted of approximately

$26940 \%$ cladocearans (mostly Daphnia sp.), 27\% adult calanoid copepods, $24 \%$ Chaoborus, 7\%

270 copepodids, and $2 \%$ adult cyclopoid copepods.

Fish were removed from the tank and placed in MS-222 for euthanization. The

272 remaining zooplankton were collected by filtering the water in each tank through a $64 \mu \mathrm{m}$

273 mesh. Zooplankton were rinsed off the mesh and into a sample cup with $70 \%$ ethanol.

274 Zooplankton were identified and enumerated under a dissecting microscope at 10 - 40x in a

275 Ward counting wheel. Zooplankton density per liter was calculated as the total number of

276 counted zooplankton divided by the total volume of water in the tank (i.e. $17 \mathrm{~L}$ ). The total

277 zooplankton consumed per minute by each fish larvae was then calculated as the difference in

278 zooplankton density at the beginning versus the end of an experiment divided by 30 minutes

279 and then divided by 2 larvae. We assumed each fish in each tank fed equally during the

280 experiment. We chose this method rather than examining gut contents to be consistent with 
281 previous experiments. Preliminary studies filling and emptying tanks with zooplankton resulted

282 in $\sim 99 \%$ recovery, providing confidence in our methodology (unpublished data).

284 three additional experiments using the same experimental setup but with bluegill Lepomis

285 machrochirus ( 13-15 $\mathrm{mm}$ in standard length) collected from a local pond. The goal of these

286 experiments was to test the limits of larval fish foraging under increasing water color by

287 reducing the foraging time and number of prey. For each experiment, fish larvae were collected

288 with light traps 24 - 48 hours before the experiment. Two larvae were placed in each tank and

289 allowed to acclimate for 24 hours prior to the introduction of zooplankton prey. A YSI sonde

290 was used to confirm that temperature, $\mathrm{pH}$, conductivity, dissolved oxygen concentrations were

291 similar across all tanks. For the first experiment, fish larvae fed for 24-hours with a relatively

292 high density of prey (i.e., 130 zooplankton per liter) to estimate daily feeding rates under ideal

293 conditions. We then conducted two experiments with reduced time and prey concentration to

294 test the limits of larval fish foraging: 1) a 10-minute feeding trial with 4 zooplankton per liter

295 and 2) a 5-minute feeding trial with 2 zooplankton per liter. Zooplankton prey remaining in each

296 tank were collected at the end of each experiment to assess fish feeding rates and prey

297 selectivity. For all three experiments, zooplankton were collected from the same pond as the

298 fish larvae and consisted of approximately 80\% cladocearans (mostly Daphnia sp.), 15\%

299 cyclopoid copepods, 3\% Chaoborus, and 2\% rotifers (Keratella sp. and Asplanchna sp.).

300 Statistical Analyses

$301 \quad$ All statistical tests were performed using the R Statistical Environment (R Core Team

302 2018). For the indirect effects experiment, we used the nlme package (Pinheiro et al. 2020) to 
303

304

305

306

307

308

309

310

311

312

313

314

315

316 sampling date. We therefore assessed differences in zooplankton density only on Day 28 with a

conduct repeated measures ANOVAs in combination with post hoc Tukey tests to assess

differences in water temperature, conductivity, $\mathrm{pH}$, and dissolved oxygen with browning treatment, time, and the interaction between time and treatment. Temperature and conductivity data were log transformed for normality. ANOVAs were computed as linear mixed models using the Ime function, including terms for random effects associated with tank number (i.e. random function) and, in some cases, autoregressive effects associated with time points being unequally spaced (i.e. corAR1 function). The anova function from the car package was used to report the results of the models (Fox and Weisberg 2019). If significant, we used the cld function in the Ismeans package (Lenth 2016) to summarize the Tukey results. Residuals from each test were calculated using the residuals function and then plotted with the plotNormalHistorgram function from the rcompanion package (Mangiafico 2020). Akaike Information Criteria were used to select the best model, particularly if autoregressive correlations improved the model.

Repeated measures ANOVA with post hoc Tukey tests were also performed on log transformed chlorophyll-a concentrations to assess differences in algal biomass with treatment, time, and interactions between treatment and time. The test was performed as described above. In addition, linear regressions of chlorophyll-a concentrations in each treatment over the first week (Days 0, 3, and 7) were performed to determine initial phytoplankton growth rates, using the slope as an estimate of added algal biomass per day.

For the zooplankton, we observed similar densities across treatments except on the last

324 Welch's ANOVA. This test is recommended when the data have high heteroscedasticity and is 
325 paired with a post hoc Games-Howell test to compute pairwise comparisons of treatments. We 326 used the welch_anova_test function from the rstatix package (Kassambara 2020). Results from

327 the Welch's ANOVAs were used to compute effect sizes based on omega squared values. abundance across treatments between Day 0 and Day 28. A Shapiro-Wilk's test confirmed data normality prior to running the ANOVA. The Ime function in the nlme package was used to run

331 the model, using tank number as a random variable. Summary results were presented with the

332 anova function and residuals were checked with the residuals and plotNormalHistogram

333 functions. Results of the Tukey test were observed using the Ismeans and cld functions as 334 described above. For the fish data in the indirect effects experiment, we again observed unequal variance 336 across treatments, and therefore, used Welch's ANOVAs with post hoc Game-Howell tests to 337 assess potential differences in zooplankton consumption and growth with water color. Because 338 we noted variability in zooplankton abundance within our treatments, we also calculated 339 Pearson correlation coefficients between zooplankton prey availability at the time of fish 340 introduction and zooplankton consumption rates after 24 hours as well as larval fish growth 341 after 6 days. $E^{*}$ Indices were calculated to determine potential differences in prey selectivity 342 with browning (Lechowicz 1982). Values were checked for normality and then a two-way 343 ANOVA was performed to test for significant differences in prey selectivity between treatment, 344 zooplankton taxa, and interactions between treatment and taxa. Tukey pairwise comparisons 345 were performed for significant results. 
347 absorbance coefficients within treatments. We therefore used linear regression analysis to

348 assess the relationship between zooplankton consumption and water color (i.e. absorbance at

$349440 \mathrm{~nm})$. For the bluegill experiments, absorbance coefficients were similar within treatments,

350 and thus, we assessed differences in zooplankton consumption across water color treatments

351 with Welch's ANOVAs, using omega squared values to estimate effect sizes. E*Indices were

352 again calculated, and two-way ANOVAs were performed to assess significant differences in prey

353 selectivity with treatment, zooplankton taxa, and their interaction. For the largemouth bass

354 experiment, this required us to bin tanks into light, moderate, and dark brown treatments

355 based on similarities in a440, with 4 replicates per treatment.

\section{Results}

\section{Indirect Effects of Browning}

358 Over the course of the 28-day experiment, there were no significant differences in

359 water temperature, $\mathrm{pH}$, or dissolved oxygen concentration among the 12 tanks with time or

360 treatment (Table 1). Conductivity did not significantly vary with time but was significantly lower

361 in the lake water treatment compared to the SuperHume treatments (Table 1). Absorbance at

$362440 \mathrm{~nm}$ was similar in the light brown and lake water treatments but significantly differed in the

363 moderate and dark brown treatments (Table 1). Water color decreased during the first week in

364 all treatments and then remained relatively constant (Figure S2). On average, absorbance

365 coefficients at $440 \mathrm{~nm}$ were $1.3 \mathrm{~m}^{-1}$ in the light brown and lake water treatments, $5.0 \mathrm{~m}^{-1}$ in the

366 moderate brown treatment, and $9.7 \mathrm{~m}^{-1}$ in the dark brown treatment. DOC concentration

367 significantly differed among the four treatments, with the light brown treatment having the 
368

369

370

371

372

373

374

375

376

377

378

379

380

381

382

383

384

385

386

387

388

lowest DOC concentration $(2.6 \mathrm{mg} / \mathrm{L})$ and the lake water treatment having the highest DOC concentration $(5.1 \mathrm{mg} / \mathrm{L}$ ) (Table 1$)$. DOC concentration initially increased by $0.3-0.8 \mathrm{mg} / \mathrm{L}$ over the first week of the experiment and then declined by $\sim 0.5 \mathrm{mg} / \mathrm{L}$ over the next 3 weeks, except in the lake water treatment, which did not significantly differ over the next three weeks (Figure S2). Interestingly, only marginal increases in DOC concentration were observed with

SuperHume additions despite an approximate 10 times increase in water color. Higher DOC concentrations in the lake water treatment, compared to the SuperHume treatments, were due to high inputs of non-chromophoric, algal-derived organic carbon in the eutrophic reservoir. Bacterial abundance significantly differed with time $\left(F_{(1)}=32.95, p=0.0004, n=12\right)$ and treatment $\left(F_{(3)}=24.11, p<0.0001, n=12\right)$. Based on the results of the Tukey test, bacterial abundance in the lake water treatment (i.e., $2.86 \times 10^{6}$ cells per $\mathrm{mL} \pm 1.4 \times 10^{5}$ S.E.) was significantly greater than all other treatments (i.e., approximately $7.1 \times 10^{5}$ cells per $\mathrm{mL} \pm 1.5 \times$ $10^{5} \mathrm{~S}$.E. in the light brown treatment and approximately $1.3 \times 10^{6}$ cells per $\mathrm{mL} \pm 9 \times 10^{5} \mathrm{~S}$.E. in the moderate and dark brown treatments). This suggests that not all bacteria were removed from the lake water treatment during the initial set-up, and bacteria were introduced with the addition of SuperHume. By the end of the experiment, bacterial abundance did not significantly differ across the light, moderate, and dark brown treatments but was significantly higher in the lake water treatment (i.e., $3.19 \times 10^{6}$ cells per $\mathrm{mL}$ in the lake water treatment compared to $\sim 2$ $x 10^{6}$ cells per $\mathrm{mL}$ in the SuperHume treatments). Interestingly, bacterial abundance differed by only $10 \pm 9 \%$ between Day 0 and Day 28 in the lake water treatment while in the low, moderate, and dark brown treatments, bacterial abundance was $64 \pm 5 \%, 35 \pm 5 \%$, and $23 \pm 3 \%$ higher on Day 28, respectively. 
406 individuals per $L \pm 10$ S.E., $p=0.003$ ) (Figure 3A). Removing one outlier from the light treatment

407 resulted in significant differences between all three SuperHume treatments at the $p \leq 0.01$

408 level. Overall, the cladoceran Bosmina sp. was the most abundant zooplankton in all treatments

409 by Day 28 (Figure 3B). Despite being the dominant zooplanktors at the beginning of the

410 experiment, copepods represented only $12 \%$ of the zooplankton community in the lake water

411 treatment and 5\% of the zooplankton community in the SuperHume treatments by Day 28 
412 (Figure 3D \& 3E). Daphnia sp. abundance was low in all treatments by Day 28, except for the

413 light brown treatment (Figure 3C). While counting the zooplankton under the microscope,

414 flocculant SuperHume was observed, but not quantified, in the guts of cladocerans (i.e.,

415 Daphnia and Bosmina) but not calanoid or cyclopoid copepods (Figure 4). Rotifers rapidly

416 decreased in abundance and were not observed in any of the treatments after Day 7.

All fish survived the 6-day incubation in the lake water and light brown treatments.

418 However, there was a 33\% mortality rate in both the moderate and dark brown treatments.

419 One dead fish was found in two replicate tanks of each treatment after 5-6 days, at which point

420 most zooplankton were visually depleted in the tanks. In the first 24 hours, fish consumed twice

421 as many prey in the lake water treatment (i.e. 610 zooplankton per larva) compared to the

422 light brown treatment ( 323 zooplankton per larva) and four times as many prey than in the

423 dark brown treatment ( 143 zooplankton per larva). However, because of the variability in

424 zooplankton abundance within treatments, zooplankton consumption by larval fish did not

425 significantly differ with water color $\left(F_{(3,3.49)}=4.79, p=0.09, n=12\right.$, est $\left.\omega^{2}=0.48: 95 \% \mathrm{Cl}[0.0,0.78]\right)$.

426 Rather, zooplankton consumption in the first 24 hours correlated highly with zooplankton

427 densities at the time fish were introduced to the experimental tanks (Pearson Correlation

428 Coefficient $=0.88, \mathrm{P}=0.0002$; Figure 5A). Proportionally, fish larvae primarily consumed Bosmina

429 in all treatments as they were the most numerous species in the tanks. However, Daphnia had

430 a higher electivity value $\left(E^{*}=0.24 \pm 0.0004\right)$, followed by Bosmina $\left(E^{*}=-0.12 \pm 0.02\right)$ and then

431 copepods $\left(E^{*}=-0.64 \pm 0.02\right)$. These differences in selectivity of zooplankton taxa were

432 statistically significant based on a two-way ANOVA $\left(F_{(2,20)}=250.9, p<0.0001, n=12\right)$. No

433 statistical differences in electivity were observed across treatment $(F(2,20)=0.44, p=0.78, n=12)$ 
434 or the interaction between treatment and taxa $\left(F_{(8,20)}=0.64, p=0.73, n=12\right)$. Note that one dark

435 brown tank had to be eliminated from the two-way ANOVA because of a lack of Daphnia at the

436 time the fish were introduced.

437 Fish growth over the 6-day feeding experiment was generally greater in the lake water

438 and light brown treatments compared to the moderate and dark brown treatments; however,

439 these differences were not significantly different $\left(F_{(3,4.02)}=3.17, p=0.15, n=12\right.$, est $\omega^{2}=0.35: 95 \%$

$440 \mathrm{Cl}[0.0,0.68])$. On average, fish grew $\sim 1.2-1.5 \mathrm{~mm}$ in the lake water and light brown

441 treatments, $\sim 0.66 \mathrm{~mm}$ in the moderate brown treatment, and $\sim 0.33 \mathrm{~mm}$ in the dark brown

442 treatment. Growth was moderately correlated with initial zooplankton abundance in the tank

443 (Pearson Correlation Coefficient $=0.62, P=0.03$; Figure 5B). After 6 days, the surviving fish larvae

444 in the moderate and dark brown treatments displayed empty and concave stomachs while

445 those in the lake water and light brown treatments were full with zooplankton prey (Figure 5C).

446 Note that previous studies have reported that it takes $4-6$ hours for larvae to fully evacuate

447 their guts (Werner 1969).

448 Direct Effects of Browning

449 In the experiment with largemouth bass, we observed no significant differences in fish

450 foraging efficiency with increased browning over the 30-minute feeding trial based on linear

451 regression (Figure 6). Fish consumed on average 2.5 zooplankton per minute \pm 0.3 S.E. across all

452 treatments, consuming mostly Daphnia sp. (percent consumed $=61 \% \pm 0.03$ S.E.) and

453 Chaoborus sp. (percent consumed $=57 \%+0.07$ S.E.) followed by copepods (percent consumed

$454=0.07 \% \pm 0.02$ S.E.). $E^{*}$ Index values significantly differ across zooplankton taxa $\left(F_{(2,27)}=71 \cdot 14, p\right.$

$455<0.0001, \mathrm{n}=12)$, with Daphnia sp. (E* Index= $0.19 \pm 0.02$ S.E.) and Chaoborus sp. (E* Index $=$ 
$0.15 \pm 0.03$ S.E.) prey preferred over copepods (E* Index $=-0.7 \pm 0.07$ S.E.). However, prey

457 selectivity did not significantly differ with treatment $\left(F_{(2,27)}=0.07, p=0.93, n=12\right)$ or the

458 interaction between treatment and zooplankton taxa $\left(F_{(4,27)}=0.38, p=0.82, n=12\right)$.

$459 \quad$ Similar patterns were observed in the experiments with bluegill (Tables 2 and 3).

460 Despite reducing zooplankton prey concentration and foraging time, no significant differences

461 in foraging rate were detected with increasing water color (Table 2). Similar to largemouth

462 bass, larval bluegill primarily consumed Daphnia sp. and Chaoborus sp. prey compared to

463 copepods in all treatments (Table 3). In the 24-hour experiment, larval bluegill in all treatments

464 consumed $\sim 80 \%$ of the zooplankton in their respective tanks, with low consumption rates for

465 rotifers (Table 2 ).

\section{Discussion}

468 development, characterized by high mortality rates that influence longer-term population

469 growth (Fuiman and Werner 2002). Here, we demonstrate that browning may add stress to this

470 critical stage by decreasing zooplankton prey availability. Browning did not, however, directly

471 alter larval fish feeding efficiency or prey selectivity, suggesting plasticity in foraging behavior

472 under varying light conditions. To our knowledge, this is the first study examining the effects of

473 freshwater browning on larval fishes. Understanding the balance between direct versus indirect

474 effects of browning on early life history stages will improve fish conservation and management

475 strategies in response to continued organic matter loading with changes in climate and land

476 use. 


\section{Indirect Effects of Browning}

481 freshwater browning is the reduction in primary production, due to increased light attenuation

482 (Wetzel 2001; Thrane et al. 2014; Solomon et al. 2015), that subsequently reduces energy flow

483 to zooplankton and fish (Jones et al. 2012; Solomon et al. 2015; Creed et al. 2018). Our study

484 supports these general observations and raises concerns for larval fish. With increasing brown

485 color, we observed a reduction in the quantity of light, decreased phytoplankton biomass, and

486 decreased zooplankton densities. In turn, the foraging rate, growth, and survival of larval

487 largemouth bass declined.

Starvation affects larval fish more than juvenile or adult stages because of their high

metabolic demands coupled with low energy reserves in their tissues (Fuiman 2002). Within 4 -

4905 days at $25-30^{\circ} \mathrm{C}$, larvae will likely starve to death given low to no food rations (Fuiman

491 2002). In the present study, after 6 days at $22-23^{\circ} \mathrm{C}$, fish larvae in the moderate and dark

492 brown treatments exhibited a 33\% mortality rate while the surviving larvae in these treatments

493 displayed concave-shaped, empty stomachs. Although we did not quantify gut fullness, these

494 observations suggest a positive relationship between browning and starvation risk. Fish larvae

495 were found dead in the darker brown treatments near the end of the experiment (Day 5 or 6 )

496 when zooplankton densities were already visibly depleted.

At the time fish larvae were introduced to our experimental tanks, zooplankton

498 densities in the moderate and dark brown treatments were 2 to 4 times less than in the light

499 brown and lake water treatments (i.e. 46 - 72 individuals per liter compared to 120 - 190 
500 individuals per liter). Daily consumption rates for larval fish are often greater than a larvae's

501 own biomass (Post 1990). We did not directly measure zooplankton or larval fish biomass in

502 our study. However, based on published length-weight regressions (larval fish: Brecker 1993;

503 zooplankton: reviewed in Watkins et al. 2011), we roughly estimate that larval fish biomass was

$504 \sim 2020 \mu \mathrm{g}$ dry weight per fish at the time of their introduction to the experimental tanks while

505 total zooplankton biomass was $\sim 1577 \pm 447 \mu \mathrm{g}$ dry weight in the dark brown treatment, 2965

$506 \pm 361 \mu \mathrm{g}$ dry weight in the moderate brown treatment, $6300 \pm 1582 \mu \mathrm{g}$ dry weight in the light

507 brown treatment, and $\sim 962 \pm 228 \mu \mathrm{g}$ dry weight in the lake water treatment. This resulted in a

508 ratio of zooplankton:fish biomass of $0.8,1.5,3.1$, and 2.5 in the dark brown, moderate brown,

509 light brown, and lake water treatments, respectively. After 24 hours, fish larvae consumed

510 approximately $0.26,0.54,1.0$, and 1.5 grams of zooplankton per gram of fish in the dark brown,

511 moderate brown, light brown, and lake water treatments, respectively. Based on data from

512 Houde and Zastrow (1990), freshwater fish should consume a minimum of $\sim 0.5-0.7$ grams of

513 prey per gram of fish per day at $23^{\circ} \mathrm{C}$ to meet mean weight-specific growth rates. This suggests

514 that larvae in the moderate and dark brown treatments were food limited.

We placed two larvae in each tank to encourage routine behavior, which resulted in a

516 fish density of $\sim 118$ larvae $\mathrm{m}^{-3}$. This is relatively high but not uncommon in nature, particularly

517 during the early months of fish hatching (Santucci et al. 2003). Previous studies have shown

518 that when zooplankton consumption outweighs zooplankton reproduction, fish larvae may

519 rapidly deplete their food source, affecting future growth and survival (Mehner and Thiel 1999;

520 Santucci et al. 2003; Hansson et al. 2007). This may occur more often in brown systems if

521 zooplankton abundances are low at the time of fish hatching. Furthermore, as surface water 
temperatures rise as a result of global climate change, fish feeding rates are predicted to

523 increase as a consequence of higher metabolic rates (van Dorst et al. 2019). Brown waters are

524 likely to increase in temperature more rapidly due to the increased absorption of solar

525 radiation (Solomon et al. 2015), further exacerbating competition for limited resources in these

526 systems.

527 Unlike prey abundance, we did not see significant differences in zooplankton

528 community composition with increased water color. Others studies have also noted minimal

529 changes in zooplankton community composition with freshwater browning, and there does not

530 seem to be a clear pattern in positive versus negative effects on specific zooplankton groups

531 (Nicolle et al. 2012; Ekvall and Hansson 2012; Kelly et al. 2014; Robidoux et al. 2015; Lebret et

532 al. 2018; Leech et al. 2018). In the present study, the zooplankton community shifted from

533 copepod to cladoceran dominated across all treatments, with smaller-bodied Bosmina the

534 dominant zooplankton prior to larval fish introduction. Abundances of large-bodied Daphnia

535 were similar in all treatments during the first two weeks of the experiment, but for unknown

536 reasons, continued to increase only in the light brown treatment (i.e., $~ 30$ individuals per $L$ at

537 Day 28). It is possible that the light brown treatment provided the ideal diet for Daphnia, with

538 sufficient carbon and nutrients from both algal- and terrestrially-derived resources (Lennon et

539 al. 2013; Gall et al. 2017; Tang et al. 2018).

540 Overall, the zooplankton community that developed in our experiment provided a

541 standard diet for fish larvae. Typically, larger crustacean zooplankton promote foraging success,

542 growth, and survival (Crowder et al. 1987; Mills et al. 1989). However, for younger larvae that

543 are gape-limited, smaller prey, like Bosmina spp., can be more beneficial (Mehner and Thiel 
544 1999). Nevertheless, zooplankton prey abundance in the moderate and dark brown treatments

545 was too low to support larval development.

546 Similar to previous studies (Batt et al. 2015; Karlsson et al. 2015; Solomon et al. 2015),

547 reduced zooplankton abundance coincided with reduced phytoplankton biomass as browning

548 increased. Interestingly, despite having similar water color, the light brown and lake water

549 treatments displayed opposite trends in phytoplankton biomass after Day 14. In the lake water

550 treatment, increased zooplankton abundance likely resulted in greater consumption of

551 phytoplankton biomass. However, we are uncertain why the same pattern did not occur in the

552 light brown treatment. It is possible that the light brown treatment, made with the COMBO

553 medium, provided phytoplankton with more nutrients for growth to keep up with zooplankton

554 consumption. We were unable to measure nutrient concentrations at the time of these

555 experiments; however, water quality monitoring data collected by the Virginia Department of

556 Environmental Quality for Sandy River Reservoir indicate generally lower nitrogen and

557 phosphorus concentrations than present in the COMBO medium.

Phytoplankton species composition and nutritional quality were not assessed as part of

559 our study; however, we recognize that these factors can also influence energy and nutrient

560 availability for zooplankton, and consequently larval fish (Taipale et al. 2018; Creed et al. 2018).

561 Because of logistics, we chose to use an artificial assemblage of green algal species that are

562 generally favorable foods. In nature, phytoplankton communities can shift towards

563 cyanobacteria with increased water color, which could further reduce zooplankton densities

564 (Ekvall et al. 2013; Robidoux et al. 2015). It is also possible that the algae used in our

565 experiment may not have been adapted to the low light conditions of brown water systems 
566 given that they were purchased from Carolina Biological. However, our results are comparable

567 to field studies examining natural communities along a water color gradient (Ask et al. 2009;

568 Karlsson et al. 2009; Thrane et al. 2014).

569 Reductions in prey consumption, and possibly less nutritious prey, ultimately led to

570 reductions in fish growth. Fish larvae in the lake water and light brown treatments, on average,

571 grew twice as fast as the larvae in the moderate brown treatment and four times faster than

572 the larvae in the dark brown treatment. Although, we recognize that there was relatively high

573 unexplained variability in growth within our treatments (e.g. fish in two replicate tanks of the

574 moderate brown treatment exhibited no growth while the third replicate exhibited relatively

575 high growth). Growth rates are important for several reasons. Larval fish become better at

576 avoiding predators and detecting prey as swimming strength and visual acuity increases with

577 body size (Fuiman 2002). In addition, larger larvae consume bigger, more energy-rich prey.

578 Growth in juvenile and adult fish is often slower in brown compared to blue lakes, resulting in a

579 smaller length-at-age (Estlander et al. 2010; Horppila et al. 2010; Benoit et al. 2016; van Dorst

580 et al. 2018), and our data suggest similar patterns for larval fish. These reductions in individual

581 growth lead to further reductions in population growth and fish biomass as lakes darken in

582 color (Karlsson et al. 2009, 2015; Finstad et al. 2014), which can alter food web structure and

583 lower fisheries yields.

Importantly, the results of our indirect effects experiment were influenced by the timing

585 of fish introduction at Day 28. If the fish had been introduced at earlier time points, when

586 zooplankton densities were similar in all treatments, we likely would have observed no effect of

587 browning on larval fish. Indeed, in systems with low prey availability, fish foraging, growth, and 
588

589

590

591

592

593

594

595

596

597

598

599

600

601

602

603

604

605

606

607

608

609

survival are reduced regardless of water color (Mehner and Thiel 1999; Santucci et al. 2003;

Hansson et al. 2007). Nonetheless, similar to our experimental results, browning has been

demonstrated in field and laboratory studies to reduce zooplankton densities (e.g. Ekvall et al.

2013; Robidoux et al. 2015; Leech et al. 2018). Moreover, it is often stated that these

differences in prey availability affect fish growth and survival, but experimental evidence is

limited. Here, we provide quantitative data on how alterations in prey densities, due to

increased browning, may affect larval fish foraging, growth, and survival in nature. We argue

that these valuable data can served as a starting point to design larger-scaled mesocosm

experiments or observational studies.

\section{Direct Effects of Browning}

When given an equal abundance of zooplankton prey, neither the foraging efficiency

nor prey selectivity of larval largemouth bass or bluegill were affected by increased browning.

Our results are similar to Stasko et al. (2012), which found no significant effect of browning on

juvenile roach feeding rates but are contrary to Jönsson et al. (2013), which reported decreases

in reactive distance and capture success of piscivorous Northern pike (Esox lucius) feeding on

roach (Rutilus rutilus) with increased water color. Weidel et al. (2017) reported significant

effects of browning on juvenile largemouth bass and bluegill foraging, but water color explained only $\sim 25-28 \%$ of the variation in foraging rates. Combined, results from our study and others

(Estlander et al. 2012; Ranaker et al. 2012; Nurminen et al. 2014) suggest that effects of

browning on fish foraging rates may be age- or species-specific.

Light intensities across all our treatments (i.e. $15-35 \mu \mathrm{mol} \mathrm{m} \mathrm{m}^{-2} \mathrm{~s}^{-1} \mathrm{PAR}$ ) may have been

adequate for larval fish foraging, resulting in the lack of direct effects. For example, Miner and 
610 Stein (1993) reported that larval bluegill successfully feed on zooplankton at light intensities

611 above 450 lux (i.e., $\sim 8 \mu \mathrm{mol} \mathrm{m} \mathrm{m}^{-2} \mathrm{~s}^{-1}$ based on the conversion factor for sunlight). Some have

612 suggested that reductions in light levels have a greater effect on later life history stages of fish

613 because of the positive relationship between sighting distance and body size (Askne and Giske

614 1993; Fiksen et al. 2002). If browning does directly affect visual foraging, it may do so by

615 limiting the thickness and daily duration of the photic zone, such that there is a spatiotemporal

616 contraction of foraging habitat critical to growth and survival. Additionally, the metabolic costs

617 associated with searching for prey may increase with reductions in light levels, particularly if

618 prey availability declines with increased browning.

Larval fish used in our experiments may have been pre-adapted to the low-light

620 environment of brown water systems. In general, the man-made reservoirs and ponds of

621 central Virginia, USA have relatively high light attenuation due to increased cDOM inputs

622 and/or increased phytoplankton growth (Figure S1). Compared to local lakes and ponds in the

623 region, our dark brown treatment increased water color approximately 10 times. However, we

624 may have seen direct effects of browning on fish feeding had we continued to add organic

625 matter to the tanks. Moreover, fish inhabiting clear, blue lakes may show a greater response to

626 freshwater browning than those in our study (Stasko et al. 2015), and we encourage further

627 experimentation with larvae from these systems.

630 visual foraging declines with browning, fish may shift from vision to other sensory mechanisms,

631 such as mechanoreception or olfactory cues, to detect zooplankton prey. For example, previous 

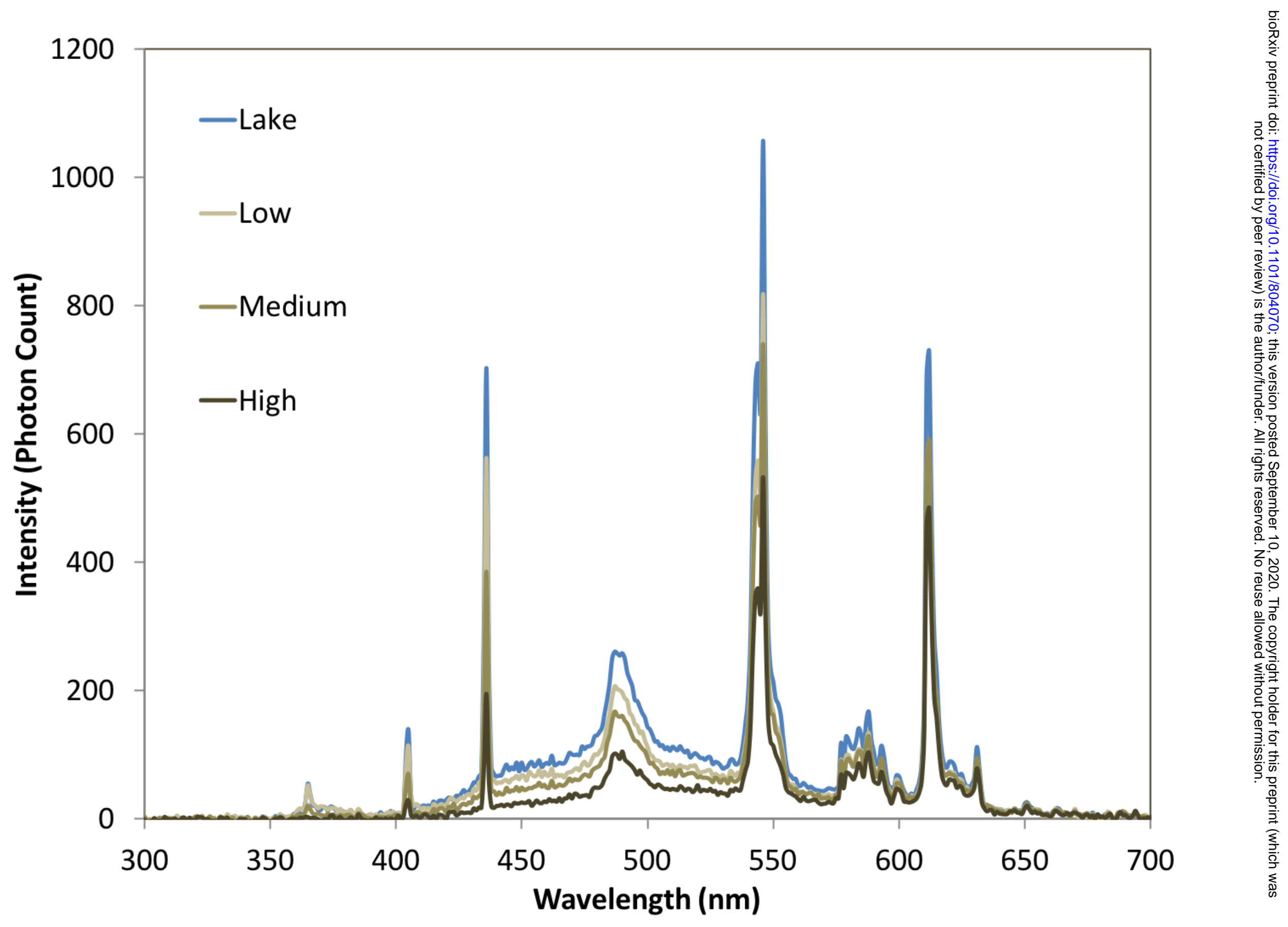
632 research ablating the function of superficial neuromasts with neomycin or streptomycin has

633 shown reduced feeding rates in marine fish larvae (Jones and Janssen 1992; Cobcroft and

634 Pankhurst, 2003; Sampson et al. 2013). Larval zebrafish have been shown to learn to use

635 mechanoreception to feed in the dark (Carillo and McHenry 2016). There is also recent

636 evidence that juvenile bluegill may actually feed more in the open pelagic water column at

637 night and horizontally migrate towards the littoral zone during the day to avoid piscivorous

638 predators (Shoup et al. 2014). Future research should investigate the potential for alternative

639 feeding strategies as waters brown in color and be cautious about our biases as human

640 researchers relying on light and vision (Cumming et al. 2018).

\section{Small Enclosures versus Natural Systems}

642 We recognize that our experiment was conducted in relatively small containers and that

643 caution must be applied when scaling up results to natural systems. Nevertheless, our

644 observations of phytoplankton, zooplankton, and fish responses to browning are similar to

645 those reported by recent field-based studies (Karlsson et al. 2009, 2015; Finstad et al. 2014 and

646 others mentioned above), providing confidence in our results. Working with fragile fish larvae is

647 challenging, and smaller containers minimize some of the logistical constraints. Yet, the small,

648 confined tank could have influenced feeding rates. Given the size of larvae used in our

649 experiments (10 - $13 \mathrm{~mm}$ ), their visual acuity, or reaction distance, is approximately one body

650 length (Werner 1969). However, we do not know how long it took larvae to search the tank.

651 Larger containers may have revealed greater differences in feeding rates across treatments,

652 similar to Weidel et al. (2017). 
656 and fish, and it is possible that the zooplankton could have clumped at the bottom of the tanks,

657 making them easier to find and capture. However, this behavioral pattern in the zooplankton

658 was not obviously apparent to us while breaking down the tanks.

660 and water color was more negative in deep lakes compared to shallow lakes within the boreal

661 region of Sweden. The authors state that the negative effects of browning associated with light

extinction and decreased primary production are minimized in shallow lakes because light often

663 reaches the lake bottom. Moreover, most fish inhabiting deeper lakes were observed in the

664 littoral zone. Moving into shallow waters may provide fish adequate light to forage in brown

665 waters, as supported by our results in shallow, experimental tanks (i.e., $~ 0.2 \mathrm{~m}$ depth).

\section{Implications and Applications}


675 highlight the need to incorporate water color (i.e. cDOM) to more accurately predict

676 recruitment strength, sustainable yields, and food web stability in systems affected by

677 browning.

678

679

680

681

682

683

684

685

686

687

688

689

690

691

692

693

694

695

696

697

698

699

700

701

702

703

704

705

706

707

708

709 


\section{Browning and larval fish foraging -- 32}

\section{Acknowledgements}

711 We thank David and Navona Hart for granting access to their pond and Mark Rolfing for his

712 assistance in counting bacteria samples. Funding for this research came from the Longwood

713 University PRISM Summer Research Program and a faculty development grant to DML from

714 Longwood University. Collection of larval bluegill and largemouth bass was approved by the

715 Virginia Department of Game and Inland Fisheries, Permit\# 051397. This manuscript was

716 improved by thoughtful comments from Sönke Johnsen, Tessa DeWalt, and two anonymous

717 reviewers.

718

719

720

721

722

723

724

725

726

727

728

729

730

731

732

733

734

735

736

737

738

739

740 


\section{References}

Aksnes, D. L. and Giske, J. 1993. A theoretical model of aquatic visual feeding. Ecol. Model. 67: 233-250.

Ask, J., Karlsson, J. and Jansson M. 2012. Net ecosystem production in clear-water and brownwater lakes. Glob. Biogeochem. Cyc. 26 7. doi:10.1029/2010GB003951.

Bartels, P., Hirsch, P. E., Svanbäck, R. and Eklöv, P. 2016. Dissolved organic carbon reduces habitat coupling by top predators in lake ecosystems. Ecosystems 19: 955-967.

Batt, R. D., Carpenter, S.R., Cole, J.J., Pace, M.L. Johnson, R.A., Kurtzweil, J.T. and Wilkinson, G.M. 2015. Altered energy flow in the food web of an experimentally darkened lake. Ecosphere 6(3): 33. http://dx.doi.org/10.1890/ES14-00241.1.

Benoît, P.O., Beisner, B.E, and Solomon, C.T. 2016. Growth rate and abundance of common fishes is negatively related to dissolved organic carbon concentration in lakes. Can. J. Fish. Aq. Sci. 73(8): 1230-1236. https://doi.org/10.1139/cjfas-2015-0340.

Breck, J. Hurry up and wait: Growth of young bluegill in ponds and in simulations with an individual-based model. Trans Amer Fish Soc 122: 467-480.

Bukaveckas, P.A. \& Robbins-Forbes, M. 2000. Role of dissolved organic carbon in the attenuation of photosynthetically active and ultraviolet radiation in Adirondack lakes. Freshw. Biol. 43(3): 339-354.

Carrillo, A, and McHenry, M.J. 2016. Zebrafish learn to forage in the dark. J. Exper. Biol. 219: 582-589. doi: 10.1242/jeb.128918.

Carpenter, S.R., Cole, J.J., Kitchell, J.F. \& Pace, M.L. 1998. Impact of Dissolved Organic Carbon, Phosphorus, and Grazing on Phytoplankton Biomass and Production in Experimental Lakes. Limnol. Oceanogr. 43(1): 73-80.

Cole, J. J., Caraco, N.F., Kling, G.W. and Kratz, T.K. 1994. Carbon dioxide supersaturation in the surface waters of lakes. Science 265: 1568-1570.

Cobcroft, J. M. and Pankhurst, P. M. 2003. Sensory organ development in cultured striped trumpeter larvae Latris lineata: implications for feeding behaviour. Mar. Freshw. Res. 54: 669-682.

Craig, N., Jones, S.E., Weidel, B.C., and Solomon, C.T. 2017. Life history constraints explain negative relationship between fish productivity and dissolved organic carbon in lakes. Ecol. Evol. 7(16): 6201-6209. doi:10.1002/ece3. 3108. 
Creed, IF, Bergström, A-K, Trick, C.G., Grimm, N.B., Hessen, D.O., Karlsson, J. ... Weyhenmeyer, G.A. 2018. Global change-driven effects on dissolved organic matter composition: Implications for food webs of northern lakes. Glob. Chan. Biol. 24: 3692-3714. https://doi.org/10.1111/gcb.14129.

Crowder, L.B., McDonald, M.E., and Rice, J.A. 1987. Understanding recruitment of Lake Michigan fishes: the importance of size-based interactions between fish and zooplankton. Can. J. Fish. Aq. Sci. 44 (2): 141-147.

Cummings ME, Endler JA, Rebecca C. Fuller. 2018. 25 Years of sensory drive: the evidence and its watery bias. Curr Zool. 64: 471-484.

Deslauriers, D., Rosburg, A.J., and Chipps, S.R. 2017. Development of a foraging model framework to reliably estimate daily food consumption by young fishes Can. J. Fish. Aq. Sci. 74: 1668-1681. https://doi.org/10.1139/cjfas-2016-0331.

de Wit, H.A., Valinia, S., Weyhenmeyer, G.A., Futter, M.N., Kortelainen, P., Austnes, K., Hessen, D.O., Räike, A., Laudon, H. and Vuorenmaa, H. 2016. Current Browning of Surface Waters Will Be Further Promoted by Wetter Climate. Environ. Sci. Tech. Let. 3 (12): $430-$ 435. DOI: 10.1021/acs.estlett.6b00396.

Douglas, R.H. and Djamgoz, M. 1990. The Visual system of fish. Chapman and Hall.

Einem, J. von and Granéli, W. 2010. Effects of fetch and dissolved organic carbon on epilimnion depth and light climate in small forest lakes in southern Sweden. Limnol. Oceanogr. 55: 920-930.

Ekvall, M.K. and Hansson L-A. 2012. Differences in Recruitment and Life-History Strategy Alter Zooplankton Spring Dynamics Under Climate-Change Conditions. PLOS ONE 7(9): e44614. https://doi.org/10.1371/journal.pone.0044614

Ekvall, M.K., De la Calle M.J., Faassen, E.J., Gustafsson, S., Lürling, M., and Hansson, L-A. 2013. Synergistic and species-specific effects of climate change and water colour on cyanobacterial toxicity and bloom formation. Freshw. Biol. 58: 2414-2422.

Erlandsson, M., Buffam, I., Folster, J., Laudon, H., Temnerud, J., Weyhenmeyer, G.A., and Bishop, K. 2008. Thirty-five years of synchrony in the organic matter concentrations of Swedish rivers explained by variation in flow and sulphate. Global Change Biol. 14: 1191-1198.

Estlander, S., Nurminen, L., Olin, M., Vinni, M., Immonen, S., Rask, M., and Lehtonen, H. 2010. Diet shifts and food selection of perch Perca fluviatilis and roach Rutilus rutilus in humic lakes of varying water colour. J. Fish Biol. 77(1): 241- 256. https://doi.org/10.1111/j.1095-8649.2010.02682.x. 
Browning and larval fish foraging -- 35

829

830

831

832

833

834

835

836

837

838

839

840

841

842

843

844

845

846

847

848

849

850

851

852

853

854

855

856

857

858

859

860

861

862

863

864

865

866

867

868

869

870

871

872
Fiksen, $\varnothing$., Aksnes, D.L., Flyum, M.H. and Giske, J. 2002. The influence of turbidity on growth and survival of fish larvae: a numerical analysis. Hydrobiologia 484: 49-59. https://doi.org/10.1023/A:1021396719733

Finstad, A. G., Helland, I.P., Ugedal, O., Hesthagen, T., and Hessen, D.O. 2014. Unimodal response of fish yield to dissolved organic carbon. Ecol. Let. 17: 36-43.

Fox J, Weisberg S. 2019. An R Companion to Applied Regression, Third edition. Sage, Thousand Oaks CA. https://socialsciences.mcmaster.ca/jfox/Books/Companion/.

Freeman, C., Evans, C.D, Monteith, D.T., Reynolds, B., and Fenner, N. 2001. Export of organic carbon from peat soils. Nature 412: 785-786. doi:10.1038/35090628.

Fuiman L.A. 2002. Special considerations of fish eggs and larvae, pp. 1-32. In L.A. Fuiman and G.W. Robert (eds.), Fishery Science, The unique contributions of early life stages. Blackwell publishing, 326 pp.

Fuiman, L.A. and R.G. Werner, eds. 2002. Fishery Science: The Unique Contributions of Early Life Stages. Blackwell Science, Oxford.

Gall, A., Kainz, M., and Rasconi, S. 2017. Daphnia magna fitness during low food supply under different water temperature and brownification scenarios. J. Limnol. 76: 161-169. DOI: 10.4081/jlimnol.2016.1450.

Guthrie, D. M. and Muntz, W. R. A. 1993. Role of vision in fish behavior. In Behavior of Teleost Fishes, 2nd edn (ed Pitcher, T. P.), pp. 89-121. London: Chapman and Hall.

Haaland, S., Hongve, D., Laudon, H., Riise, G., and Vogt, R.D. 2010. Quantifying the drivers of the increasing colored organic matter in boreal surface waters. Environ. Sci. Tech. 44: 29752980.

Hansson, L-A., Nicolle, A., Brodersen, J., Romare, P., Anders Nilsson, P., Brönmark, C., \& Skov, C. 2007. Consequences of fish predation, migration and juvenile ontogeny on zooplankton spring dynamics. Limnol. Oceanogr. 52: 696-706.

Houde, E.D. and Zastrow, C.E. 1993, Ecosystem- and taxon-specific dynamic and energetics properties of larval fish assemblages. Bulletin of Marine Science 53: 290-335.

Horppila, J., Olin, M., Vinni, M., Estlander, S., Nurminen, L., Rask, M., Ruuhijärvi, J. and Lehtonen, H. 2010. Perch production in forest lakes: the contribution of abiotic and biotic factors. Ecol. Freshw. Fish 19: 257-266. 
Jones, R.I. 1992. The influence of humic substances on lacustrine planktonic food chains. Hydrobiolog. 229: 73-91.

Jones, W. R. and Janssen, J. 1992. Lateral line development and feeding behavior in the mottled sculpin, Cottus bairdi (Scorpaeniformes: Cottidae). Copeia 1992: 485-492.

Kassambara, A. 2020. Rstatix: Pipe-Friendly framework for basic statistical tests. https://rpkgs.datanovia.com/rstatix/

Karlsson, J., Byström, P., Ask, J., Ask, P., Persson, L. and Jansson, M. 2009. Light limitation of nutrient-poor lake ecosystems. Nature 460(7254): 506-509.

Karlsson, J., Bergstrom, A.K., Bystrom, P., Gudasz, C., Rodriguez, P., and Hein, C. 2015. Terrestrial organic matter input suppresses biomass production in lake ecosystems. Ecology 96: 2870- 2876. doi:10.1890/15-0515.1.

Keast, A., and Welsh L. 1968. Daily feeding periodicities, food uptake rates, and dietary changes with hour of day in some lake fishes. J. Fish. Res. Board. Can. 25: 1133-1144.

Kilham, S.S., Kreeger, D.A., Lynn, S.G., Goulden, C.E., and Herrera, L. 1998. COMBO: a defined freshwater culture medium for algae and zooplankton. Hydrobiolog. 377: 147-159.

Kirk, J.T. O. 1994. Light and photosynthesis in aquatic ecosystems. Melbourne: Cambridge University Press. http://www.loc.gov/catdir/toc/cam025/93037395.html

Koizumi S., Craig, N., Zwart, J.A., Kelly, P.T., Ziegler, J.P., Weidel, B.C., Jones, S.E., \& Solomon, C.T. 2018. Experimental whole-lake dissolved organic carbon increase alters fish diet and density but not growth or productivity. Can. J. Fish. Aq. Sci. 75: 1859-1867. https://doi.org/10.1139/cjfas-2017-0283.

Kritzberg, E.S. and Ekström, S.M. 2012. Increasing iron concentrations in surface waters - a factor behind brownification? Biogeosciences 9(4): 1465-1478.

Lebret, K., Langenheder, S., Colinas, N., Östman, Ö., \& Lindström, E.S. 2018. Increased water colour affects freshwater plankton communities in a mesocosm study. Aq. Microb. Ecol. 81: 1-17. https://doi.org/10.3354/ame01858

Lechowicz, M.J. 1982. The sampling characteristics of electivity indices. Oecologia 52: 22-30.

Leech, D.M. and Johnsen, S. 2009. Light and biological receptors. In Encyclopedia of Inland Waters. Editor, G. Likens. Pp. 671-681. 
Leech, D.M., Pollard, A.I., Labou, S.G., and Hampton, S.E. 2018. Fewer blue lakes and more murky lakes in the U.S.: Implications for planktonic food webs. Limnol. Oceanogr. 63: 2661-2680. doi.org/10.1002/Ino.10967.

Lenth, R.V. 2016. Least-Squares Means: The R Package Ismeans. Journal of Statistical Software, 69(1), 1-33.doi:10.18637/jss.v069.i01

Mangiafico, S. 2020. Rcompanion: Functions to Support Extension Education Program Evaluation. http://rcompanion.org

Mehner, T. and Thiel, R. 1999. A review of predation impact by 0+ fish on zooplankton in fresh and brackish waters of the temperate northern hemisphere. Environ. Biol. Fish. 56: 169-181.

Mills, E. L., Sherman, R. and Robson, D.S. 1989. Effect of zooplankton abundance and body size on growth of age-0 yellow perch (Perca flavescens) in Oneida Lake, New York, 19751986. Can. J. Fish. Aq. Sci. 46: 880- 886.

Miner, J.G., and R.A. Stein. 1993. Interactive influence of turbidity and light on larval bluegill (Lepomis macrochirus) foraging. Can. j. Fish. Aquat. Sci. 50: 704-788.

Monteith, D.T., Stoddard, J.L., Evans, C.D., de Wit, Heleen A., Forsius, M., Høgåsen, T., Wilander, A., Skjelkvåle, B.L., Jeffries, D.S., Vuorenmaa, J., Keller, B., Kopácek, J. and Vesely, J. 2007. Dissolved organic carbon trends resulting from changes in atmospheric deposition chemistry. Nature 450(7169): 537-540.

Morris D.P., Zagarese, H., Williamson, C.E., Balseiro, E.G., Hargreaves, B.R., Modenutti, B., Moeller, R., and Queimalinos, C. 1995. The attenuation of solar UV radiation in lakes and the role of dissolved organic carbon. Limnol. Oceanogr. 40: 1381-1391.

Nicolle, A., Hallgren P., Von Einem J., Kritzberg E.S., Graneli W., Persson A. ... Hansson, L-A. 2012. Predicted warming and browning affect timing and magnitude of plankton phenological events in lakes: an enclosure study. Freshw. Biol. 57: 684-695.

Nurminen, L, Estlander S, Olin M, and Lehtonen H. 2014. Feeding efficiency of planktivores under disturbance, the effect of water colour, predation threat and shoal composition: feeding of planktivores under disturbance. J. Fish Biol. 84: 1195-1201.

Övergaard, R. 2019. The effects of different browning agents SuperHume, HuminFeed, and Reverse Osmosis Concentrate on the fitness and survival of Daphnia magna (Dissertation). Retrieved from http://urn.kb.se/resolve?urn=urn:nbn:se:uu:diva-392705 
958 959

960

961

962

963

964

965

966

967

968

969

970

971

972

973

974

975

976

977

978

979

980

981

982

983

984

985

986

987

988

989

990

991

992

993

994

995

996

997

998

999

1000

1001

Pinheiro J, Bates D, DebRoy S, Sarkar D, R Core Team (2020). nlme: Linear and Nonlinear Mixed Effects Models. R package version 3.1-149. https://CRAN.R-project.org/package=nlme.

Porter, K.G. and Feig, Y. S. 1980. The use of DAPI for identifying and counting aquatic microflora. Limnol. Oceanogr. 25: doi: 10.4319/lo.1980.25.5.0943.

R Core Team. 2018. R: A language and environment for statistical computing. R Foundation for Statistical Computing, Vienna, Austria. URL https://www.R-project.org/.

Ranåker L, Jönsson M, Nilsson PA, and Brönmark C. 2012. Effects of brown and turbid water on piscivore-prey fish interactions along a visibility gradient. Freshw. Biol. 57(9): 17611768.

Sampson, J.A., Duston, J., and Croll, R.P. 2013. Superficial neuromasts facilitate non-visual feeding by larval striped bass (Morone saxatilis). J. Exper. Biol. 216: 3522-3530. doi: 10.1242/jeb.087395.

Santucci, V.J., Jr., and Wahl, D.H. 2003. The effects of growth, predation, and first-winter mortality on recruitment of bluegill cohorts. Trans. Amer. Fish. Soc. 132: 346-360.

Seekell, D. A., Lapierre, J.-F., Ask, J., Bergström, A.-K., Deininger, A., Rodríguez, P., \& Karlsson, J. 2015. The influence of dissolved organic carbon on primary production in northern lakes. Limnol. Oceanogr. 60: 1276-1285. doi:10.1002/Ino.10096.

Seekell, D. A., Byström, P. and Karlsson, J. 2018. Lake morphometry moderates the relationship between water color and fish biomass in small boreal lakes. Limnol. Oceanogr. 63: 21712178. doi:10.1002/Ino.10931

Shoup, D.E., Boswell, K.M. and Wahl, D.H. 2014. Diel Littoral-Pelagic Movements by Juvenile Bluegills in a Small Lake. Trans. Amer. Fish. Soc. 143(3): 796-801.

Solomon, C. T., S. E. Jones, B. C. Weidel, and others. 2015. Ecosystem Consequences of Changing Inputs of Terrestrial Dissolved Organic Matter to Lakes: Current Knowledge and Future Challenges. Ecosystems 18: 376-389. doi:10.1007/s10021-015-9848-y

Stasko, A.D., Gunn, J.M., and Johnston, T.A. 2012. Role of ambient light in structuring north temperate fish communities: potential effects of increasing dissolved organic carbon concentration with a changing climate. Environ. Rev. 20(3): 173-190. doi:10.1139/a2012010.

Stasko AD, Johnston TA, and Gunn JM. 2015. Effects of water clarity and other environmental factors on trophic niches of two sympatric piscivores. Freshw. Biol. 60: 1459-1474.

Taipale, S. J., Kahilainen, K. K., Holtgrieve, G. W., and Peltomaa, E. T. 2018. Simulated eutrophication and browning alters zooplankton nutritional quality and determines juvenile fish growth and survival. Ecol. Evol. 8(5): 2671-2687. doi:10.1002/ece3.3832. 
Browning and larval fish foraging -- 39

1002

1003

1004

1005

1006

1007

1008

1009

1010

1011

1012

1013

1014

1015

1016

1017

1018

1019

1020

1021

1022

1023

1024

1025

1026

1027

1028

1029

1030

1031

1032

1033

1034

1035

1036

1037

1038

1039

1040

1041

1042

1043

1044

1045
Tang, Y., Yang, X., Xu, R., Zhang, X., Liu, Z., Zhang, Y. and Dumont, H. J. 2019. Heterotrophic microbes upgrade food value of a terrestrial carbon resource for Daphnia magna. Limol. Oceanogr. 64: 474-482. doi:10.1002/Ino.11052.

Thrane, J.-E., Hessen, D.O. and Andersen, T. 2014. The Absorption of Light in Lakes: Negative Impact of Dissolved Organic Carbon on Primary Productivity. Ecosystems 17: 1040-1052.

van Dorst, R.M., Gårdmark, A., Svanbäck, R., Beier, U., Weyhenmeyer, G.A., and Huss, M. 2019. Warmer and browner waters decrease fish biomass production. Global Change Biol. 25: 1395- 1408. https://doi.org/10.1111/gcb.14551.

Vasconcelos, F.R., Diehl, S., Rodríguez, P., Karlsson, J., and Byström, P. 2018. Effects of terrestrial organic matter on aquatic primary production as mediated by pelagic-benthic resource fluxes. Ecosystems 21: 1255. https://doi.org/10.1007/s10021-017-0217-x.

Vasconcelos, FR, Diehl, S, Rodríguez, P, Hedström, P, Karlsson, J, and Byström, P. 2019. Bottomup and top-down effects of browning and warming on shallow lake food webs. Global Change Biol. 25: 504- 521. https://doi.org/10.1111/gcb.14521.

Watkins, J., Rudstam, L., and Holeck, K. 2011. Length-weight regressions for zooplankton biomass calculations - A review and a suggestion for standard equations. Technical Report. Cornell University. Available at https://hdl.handle.net/1813/24566.

Weidel, B.C., Baglini, K., Jones, S.E., Kelly, P.T., Solomon, C.T., and Zwart, J.A. 2017. Light climate and dissolved organic carbon concentration influence species-specific changes in fish zooplanktivory. Inland Waters 7(2): 210-217. doi:10.1080/20442041.2017.1329121.

Werner, R.G. 1969. Ecology of Limnetic Bluegill (Lepomis macrochirus) Fry in Crane Lake, Indiana. The American Midland Naturalist 81(1): 164-181.

Wetzel, R. G. 2001. Limnology: Lake and river ecosystems, 3rd ed. Academic Press.

Weyhenmeyer, G.A., Müller, R.A., Norman, M., and Tranvik, L.J. 2016. Sensitivity of freshwaters to browning in response to future climate change. Climatic Change 134: 225-239. https://doi.org/10.1007/s10584-015-1514-z.

Williamson, C. E., Overholt, E.P., Pilla, R.M., Leach, T.H., Brentrup, J.A., Knoll, L.B., Mette, E.M. and Moeller, R.E. 2015. Ecological consequences of long-term browning in lakes. Scientific Reports 5: srep18666. doi:10.1038/srep18666.

Wylie, J.L. and Currie, D.J. 1991. The relative importance of bacteria and algae as food sources for crustacean zooplankton. Limnol. Oceanogr. 36: 708-728. doi: 10.4319/lo.1991.36.4.0708. 
1046

1047

1048

1049

1050

Table 1. Mean \pm S.E. of major physical and chemical parameters across water color treatments. Significance is denoted in the last column, with, $T=$ treatment effect, $D=$ Day, I = Treatment:Day interaction, and NS = not significant. Lowercase letters indicate which treatments were significantly different from one another based on treatment effect.

\begin{tabular}{|c|c|c|c|c|c|}
\hline & Lake Water & $\begin{array}{l}\text { Light } \\
\text { Brown }\end{array}$ & $\begin{array}{l}\text { Moderate } \\
\text { Brown }\end{array}$ & $\begin{array}{l}\text { Dark } \\
\text { Brown }\end{array}$ & Significance \\
\hline $\begin{array}{l}\text { Temperature } \\
\left({ }^{\circ} \mathrm{C}\right)\end{array}$ & $22.1 \pm 0.18$ & $22.09 \pm 0.16$ & $22.04 \pm 0.16$ & $22.03 \pm 0.15$ & $\begin{array}{l}\text { (T) NS } \\
\text { (D) NS } \\
\text { (I) NS }\end{array}$ \\
\hline $\begin{array}{l}\text { Dissolved } \\
\text { Oxygen } \\
\text { (mg/L) }\end{array}$ & $9.05 \pm 0.09$ & $9.12 \pm 0.09$ & $8.89 \pm 0.04$ & $8.83 \pm 0.03$ & $\begin{array}{l}\text { (T) NS } \\
\text { (D) }<0.0001 \\
\text { (I) NS }\end{array}$ \\
\hline $\begin{array}{l}\text { Conductivity } \\
(\mathrm{mS} / \mathrm{cm})\end{array}$ & $\begin{array}{c}0.08 \pm 0 \\
a\end{array}$ & $0.25 \pm \frac{0.01}{b}$ & $\begin{array}{c}0.25 \pm 0 \\
b\end{array}$ & $0.25 \pm \frac{0.01}{b}$ & $\begin{array}{l}\text { (T) }<0.0001 \\
\text { (D) } 0.01 \\
\text { (I) NS }\end{array}$ \\
\hline $\mathrm{pH}$ & $7.36 \pm 0.04$ & $7.25 \pm 0.04$ & $7.15 \pm 0.22$ & $7.14 \pm 0.02$ & $\begin{array}{l}\text { (T) NS } \\
\text { (D) NS } \\
\text { (I) NS }\end{array}$ \\
\hline a440 & $\begin{array}{c}1.77 \pm 0.65 \\
a\end{array}$ & $0.99 \pm 0.08$ & $4.84 \pm \frac{ \pm}{b} 0.12$ & $9.83 \pm 0.17$ & $\begin{array}{l}\text { (T) }<0.0001 \\
\text { (D) } 0.003 \\
\text { (I) NS }\end{array}$ \\
\hline Chl-a (ug/L) & $\begin{array}{c}16.34 \pm 2.69 \\
a b\end{array}$ & $\begin{array}{c}29.65 \pm 3.83 \\
b\end{array}$ & $\begin{array}{c}12.4 \pm 2.12 \\
a\end{array}$ & $\begin{array}{c}8.66 \pm 1.57 \\
a\end{array}$ & $\begin{array}{l}\text { (T) }<0.0001 \\
\text { (D) } 0.004 \\
\text { (I) } 0.0002\end{array}$ \\
\hline $\mathrm{DOC}(\mathrm{mg} / \mathrm{L})$ & $5.22 \pm 0.05$ & $2.58 \pm 0.07$ & $3.40 \pm \frac{0.06}{c}$ & $4.66 \pm 0.07$ & $\begin{array}{l}\text { (T) }<0.0001 \\
\text { (D) } 0.02 \\
\text { (I) NS }\end{array}$ \\
\hline
\end{tabular}

1051

1052

1053

1054

1055

1056

1057

1058 
Table 2. Results from the three foraging experiments with larval bluegill (Lepomis machrochirus), including the mean \pm S.E. consumption rates. The approximate total number of each zooplankton type in the tanks at the start of a feeding trial is provided in parentheses in the first column. Welch's ANOVA results and omega-squared estimates of effect size were calculated for total zooplankton consumed only.

\section{Consumption Rates}

(day ${ }^{-1}$ larva $^{-1}$ or min $^{-1}$ larva $^{-1}$ )

Light

Moderate

Dark

Experiment 1: 24 hours, 130 zooplankton $\mathrm{L}^{-1}$

$\begin{array}{rccc}\text { Large Cladocerans (210) } & 99 \pm 4 & 101 \pm 2 & 102 \pm 1 \\ \text { Small Cladocerans (1817) } & 884 \pm 7 & 876 \pm 8 & 876 \pm 11 \\ \text { Chaoborus (33) } & 23 \pm 0 & 23 \pm 0 & 23 \pm 0 \\ \text { Copepods (47) } & 16 \pm 0.1 & 16 \pm 0.2 & 16 \pm 0.2 \\ \text { Rotifers (77) } & 33 \pm 1 & 34 \pm 1 & 35 \pm 0.1 \\ \text { Total (2183) } & 1055 \pm 6 & 1051 \pm 9 & 1052 \pm 10\end{array}$

Welch's ANOVA $\quad F_{(2,5.7)}=0.081, p=0.92, n=12$

Omega Squared Estimate est $\omega^{2}=0.18: 95 \% \mathrm{Cl}[0.0,0.68]$

Experiment 2: 10 minutes, 4 zooplankton $\mathrm{L}^{-1}$

$\begin{array}{rccc}\text { Large Cladocerans (39) } & 2 \pm 0.03 & 2 \pm 0.1 & 2 \pm 0.03 \\ \text { Chaoborus (5) } & 0.3 \pm 0 & 0.3 \pm 0 & 0.25 \pm 0 \\ \text { Copepods (23) } & 1 \pm 0.02 & 1 \pm 0.04 & 0.8 \pm 0.1 \\ \text { Total (67) } & 3 \pm 0.01 & 3 \pm 0.2 & 2.8 \pm 0.4\end{array}$

Welch's ANOVA $\mathrm{F}_{(2,4.0)}=1.53, \mathrm{p}=0.32, \mathrm{n}=12$

Omega Squared Estimate est $\omega^{2}=0.08: 95 \% \mathrm{Cl}[0.0,0.47]$

Experiment 3: 5 minutes, 2 zooplankton $\mathrm{L}^{-1}$

$\begin{array}{rccc}\text { Large Cladocerans (22) } & 1.3 \pm 0.2 & 1.5+0.08 & 1.4 \pm 0.2 \\ \text { Small Cladoceran (7) } & 0.3 \pm 0.1 & 0.5+0.1 & 0.38 \pm 0.1 \\ \text { Copepods (11) } & 0.5 \pm 0.2 & 0.7+0.2 & 0.5 \pm 0.1 \\ \text { Total (40) } & 2 \pm 0.3 & 2 \pm 0.2 & 2 \pm 0.5\end{array}$

Welch's ANOVA $\mathrm{F}_{(2,5.3)}=1.45, \mathrm{p}=0.31, \mathrm{n}=12$

Omega Squared Estimate est $\omega^{2}=0.08: 95 \% \mathrm{Cl}[0.0,0.43]$ 
1064 1065 1066 1067 1068

Table 3. $E^{*}$ Index values from the three foraging experiments with larval bluegill (Lepomis machrochirus), including the mean \pm S.E. for prey selectivity. The $E^{*}$ Index ranges from 1 to -1 , where 1 represents a strong selection for a prey type, -1 equals strong avoidance of a prey type, and 0 equals random feeding. Two-way ANOVAs were performed to assess significant differences with treatment, zooplankton taxa, and their interaction.

\section{E* Index}

Light Moderate Dark

Experiment 1: 24 hours, 130 zooplankton $\mathrm{L}^{-1}$

$\begin{array}{rccc}\text { Large Cladocerans } & -0.007 \pm 0.02 & 0.004 \pm 0.004 & 0.007 \pm 0.006 \\ \text { Small Cladocerans } & 0.01 \pm 0.005 & 0.003 \pm 0.005 & 0.003 \pm 0.005 \\ \text { Chaoborus } & 0.02 \pm 0.002 & 0.02 \pm 0.005 & 0.02 \pm 0.002 \\ \text { Copepods } & 0.01+0.003 & 0.006 \pm 0.003 & -0.01 \pm 0.005 \\ \text { Rotifers } & -0.04 \pm 0.02 & -0.04 \pm 0.01 & -0.03 \pm 0.004\end{array}$

ANOVA Results: Treatment: $\mathrm{F}_{(2,45)}=0.09 ; \mathrm{p}=0.91, \mathrm{n}=12$

Zooplankton Taxa: $F_{(2,45)}=20.62 ; p<0.0001, n=12$

Treatment:Zooplankton: Taxa: $F_{(8,45)}=0.84 ; p=0.57, n=12$

\section{Experiment 2: 10 minutes, 4 zooplankton $\mathrm{L}^{-1}$}

$$
\begin{array}{rccc}
\text { Large Cladocerans } & 0.004 \pm 0.008 & 0.006 \pm 0.02 & -0.03 \pm 0.06 \\
\text { Chaoborus } & 0.01 \pm 0.002 & 0.04 \pm 0.02 & 0.06 \pm 0.06 \\
\text { Copepods } & -0.02 \pm 0.009 & -0.05 \pm 0.007 & -0.06 \pm 0.03
\end{array}
$$

ANOVA Results: Treatment: $\mathrm{F}_{(2,27)}=0.10 ; \mathrm{p}=0.91, \mathrm{n}=12$

Zooplankton Taxa: $F_{(2,27)}=4.81 ; p=0.02, n=12$

Treatment:Zooplankton: Taxa: $F_{(4,27)}=0.72 ; p=0.58, n=12$

\section{Experiment 3: 5 minutes, 2 zooplankton $\mathrm{L}^{-1}$}

$$
\begin{array}{rccc}
\text { Large Cladocerans } & 0.16 \pm 0.07 & -0.01 \pm 0.07 & 0.10 \pm 0.06 \\
\text { Small Cladocerans } & -0.23 \pm 0.26 & -0.05 \pm 0.08 & -0.2 \pm 0.3 \\
\text { Copepods } & -0.25 \pm 0.29 & -0.02 \pm 0.03 & -0.08 \pm 0.07
\end{array}
$$

ANOVA Results: Treatment: $F_{(2,27)}=0.15 ; p=0.86, n=12$

Zooplankton Taxa: $F_{(2,27)}=1.96 ; p=0.17, n=12$

Treatment:Zooplankton: Taxa: $F_{(4,27)}=0.48 ; p=0.75, n=12$ 
Browning and larval fish foraging -- 43

1069

1070

1071

1072

1073

1074

1075

1076

1077

1078

1079

1080

1081

1082

1083

1084

1085

1086

1087

1088

1089

1090

1091

1092

1093

1094

1095

1096

1097

1098

1099

1100

1101

1102

1103

1104

1105

1106

1107

1108

1109

1110

1111

1112

\section{Figure Legends}

Figure 1. Spectral characteristics of the four treatments measured in photon counts per wavelength. Data were collected by an Ocean Optics Red Tide USB650 UV spectrophotometer from 250 to $800 \mathrm{~nm}$ with the sensor placed at the bottom of the tank pointing straight up toward the overhead grow lamps.

Figure 2. Mean phytoplankton biomass, as estimated by chlorophyll-a concentration, in the four treatments during the 28-day experiment. Error bars represent the standard error of three replicate tanks per treatment. Phytoplankton biomass increased in all treatments during the first 7 days but was comparatively lower in treatments with increased water color throughout the experiment.

Figure 3. Zooplankton densities (individuals per Liter) in the four treatments during the 28-day experiment. Error bars represent the standard error of three replicate tanks per treatment. The top panel displays changes in total zooplankton densities $(A)$ while the bottom panels display individual zooplankton genera or groups, including the cladocerans Bosmina (B) and Daphnia (C) as well as cyclopoid (D) and calanoid (E) copepods. In general, the zooplankton community shifted from copepod to cladoceran dominated and abundance was significantly lower in treatments with increased water color.

Figure 4. Flocculant organic matter was observed in the guts of cladocerans, including Bosmina and Daphnia, but not copepods in the moderate and dark brown treatments. Brown arrows highlight cladoceran gut contents. Image taken at 40x magnification.

Figure 5. Daily prey consumption (A) and total growth over 6 days (B) in relation to zooplankton prey availability at the time fish were introduced to the experimental tanks. Note that there are 2 points for the moderate brown treatment with $\sim 1400$ zooplankton prey and $0 \mathrm{~mm}$ growth. After 6-days, surviving larval fish in the moderate and dark brown treatments displayed concave empty stomachs while those in the light brown and lake water treatments had full stomachs. Photos show example larvae from the light brown and dark brown treatments (C). Red tick marks below fish are in millimeters.

Figure 6. Zooplankton consumption rates for larval largemouth bass with increasing water color, as measured by absorbance at $440 \mathrm{~nm}$. When given equal prey concentrations in all treatments (i.e., 20 individuals per liter), there was no significant difference in the number of prey consumed during the 30-minute feeding trial. This suggests no direct effect of browning on visual foraging. 
Browning and larval fish foraging -- 44

1113

1114

1115

1116

1117

1118

1119

1120

1121

1122

1123

\section{Supplementary Materials}

Figure S1. Representative downwelling irradiance curves for photosynthetically active radiation (PAR) in Sandy River Reservoir and Hart Pond. Both are located near Farmville, VA, USA and were used as our study systems to collect larval fish and zooplankton. Measurements were taken with a Biospherical Instruments, Inc. BIC profiling radiometer in June 2014.

Figure S2. Mean \pm S.E. of $(A) a_{440}$ and $(B)$ dissolved organic carbon concentrations over time during the Indirect Effects experiment. Data were collected at Day 0, 3, 7, 14, 21, and 28 as described in the Methods. 


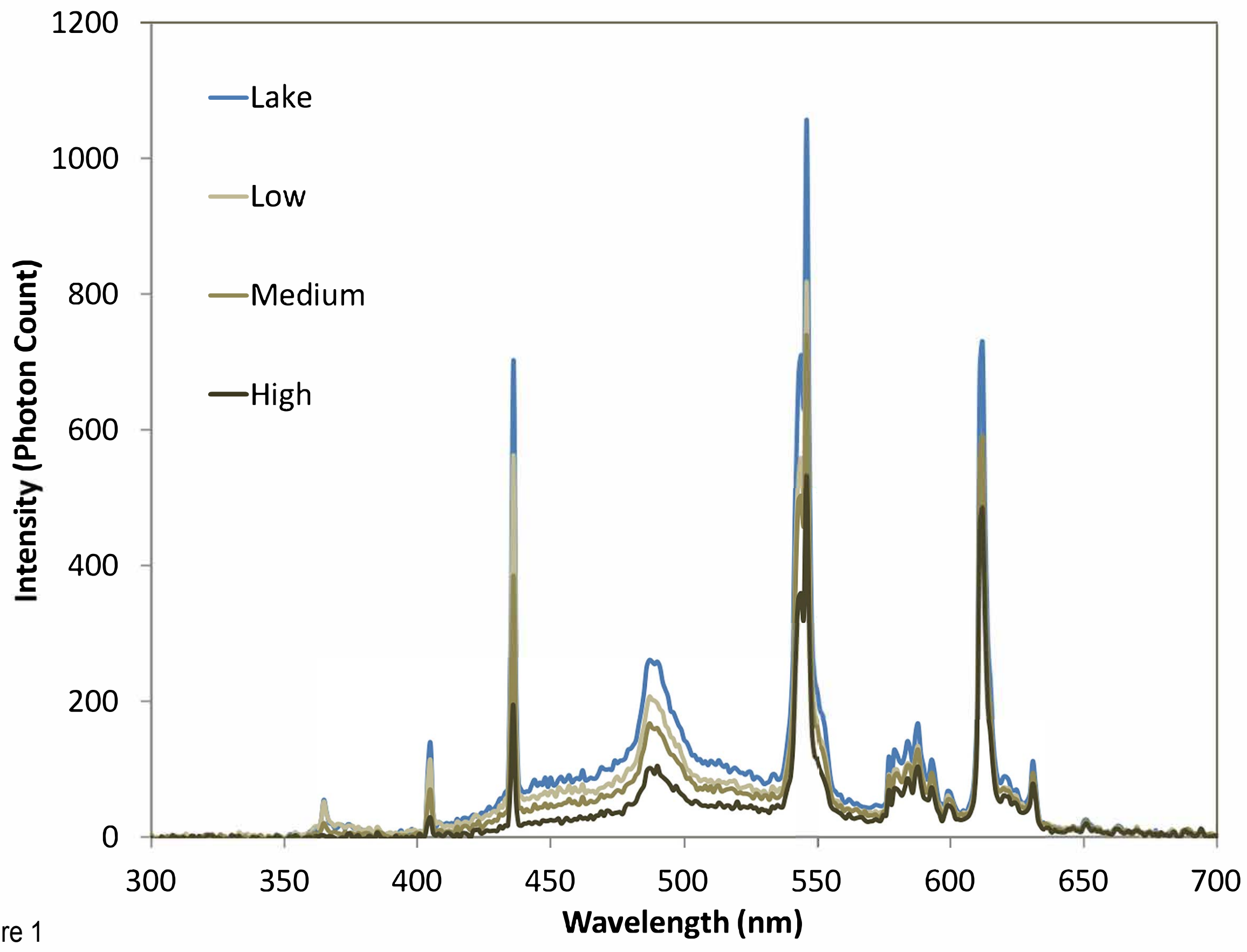



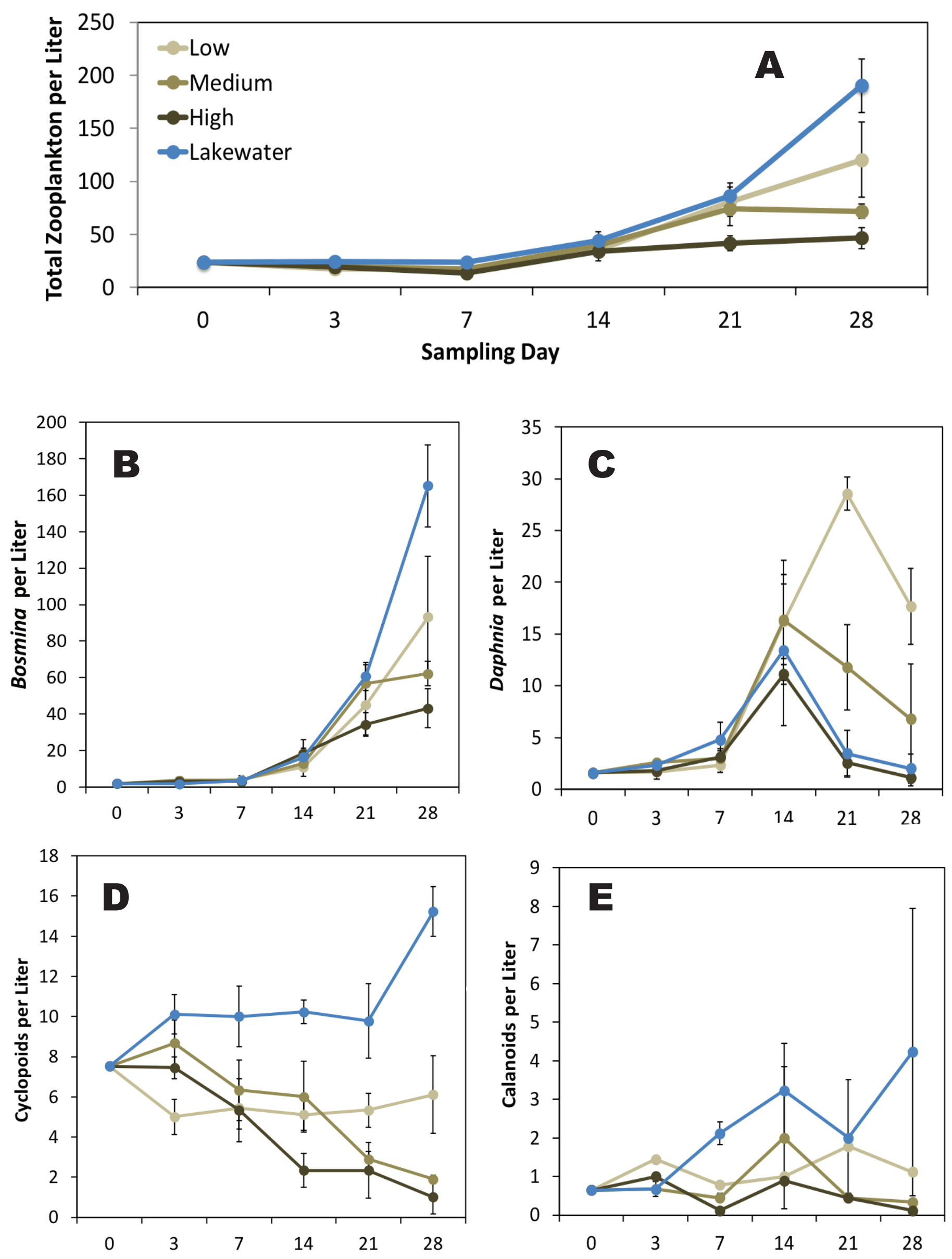

Figure 3 


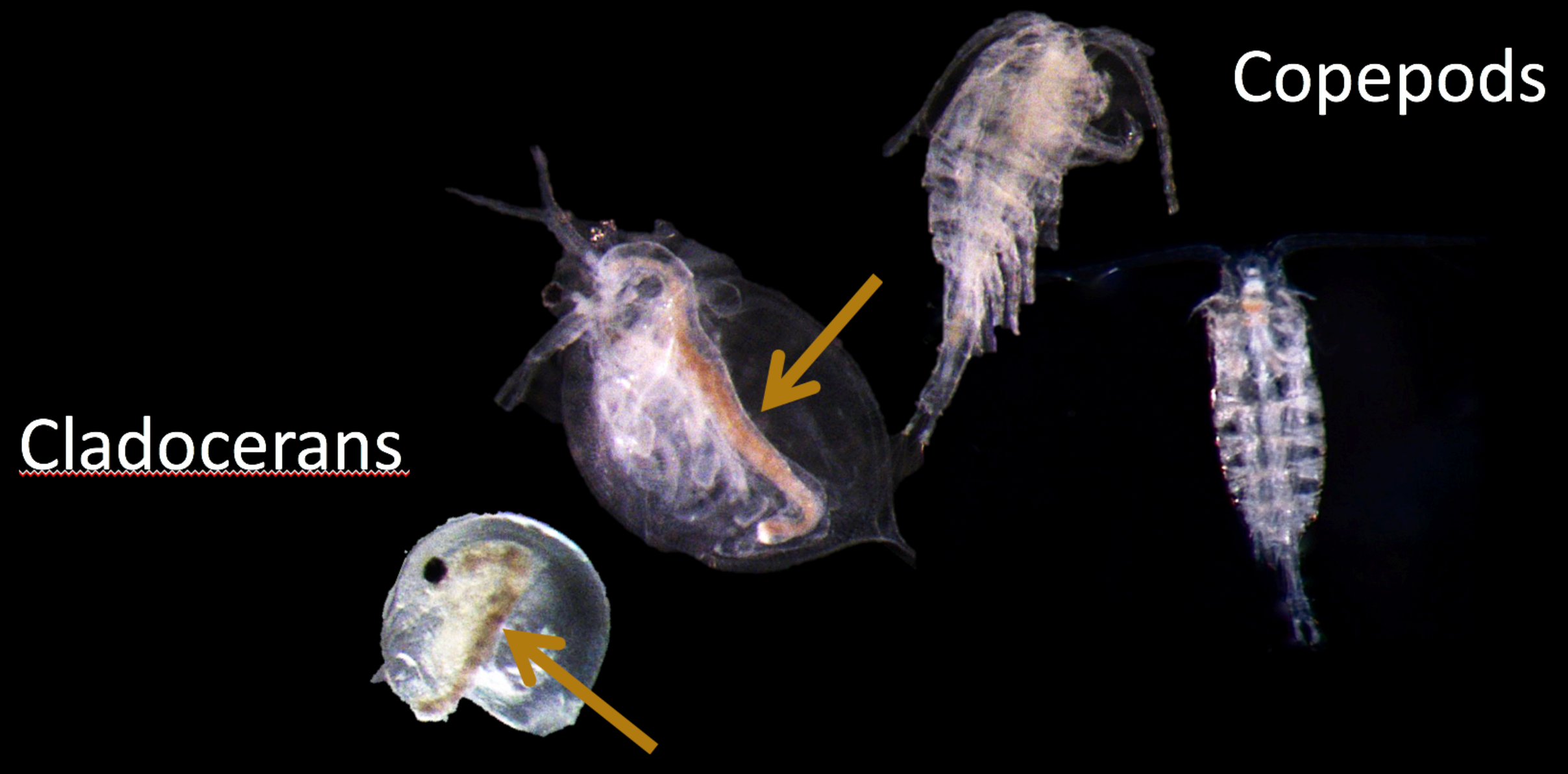

Figure 4 

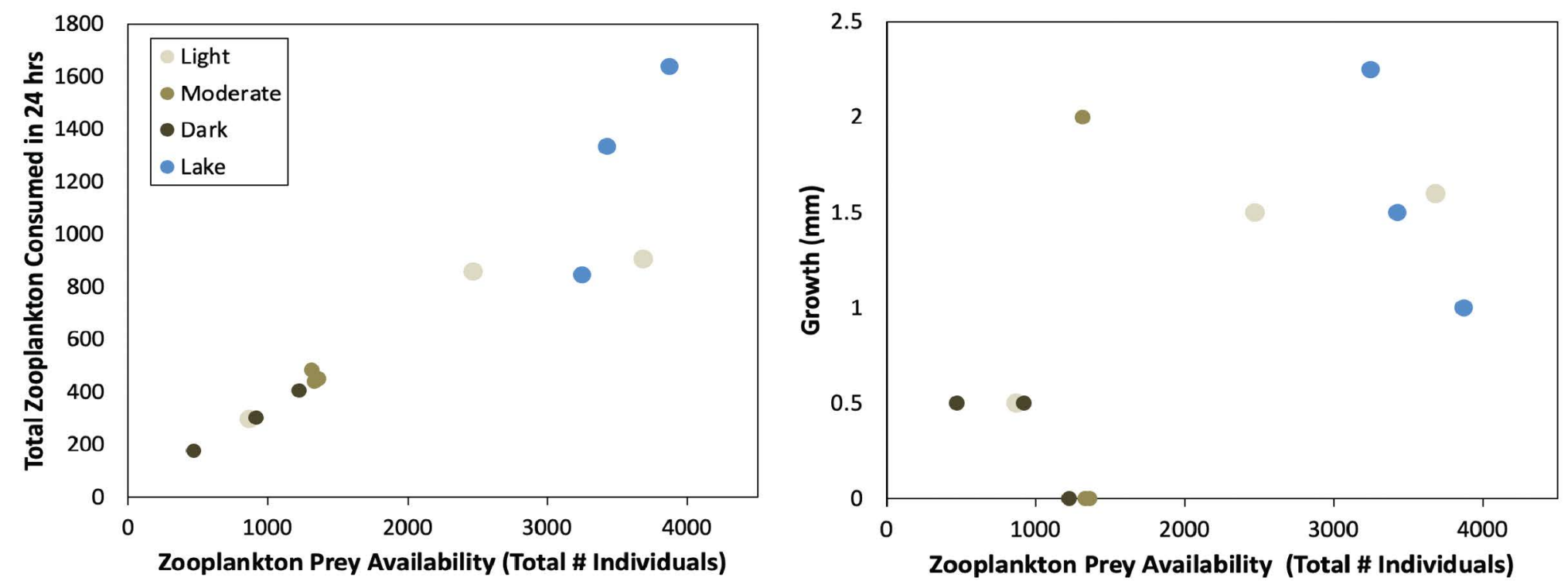

C

\section{Light Brown}

\section{1}

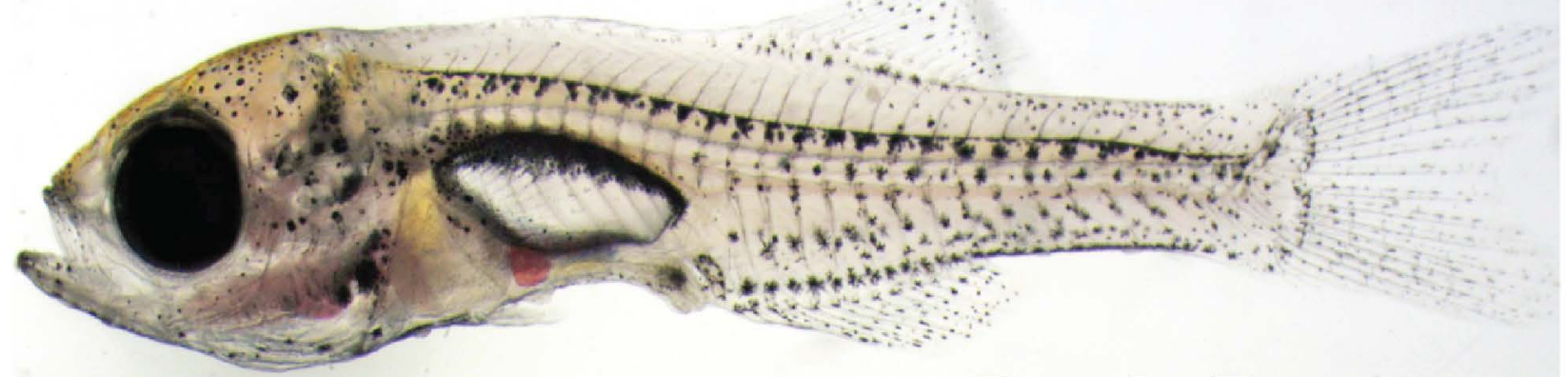

\section{Dark Brown}

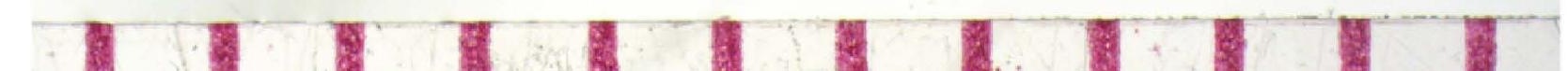




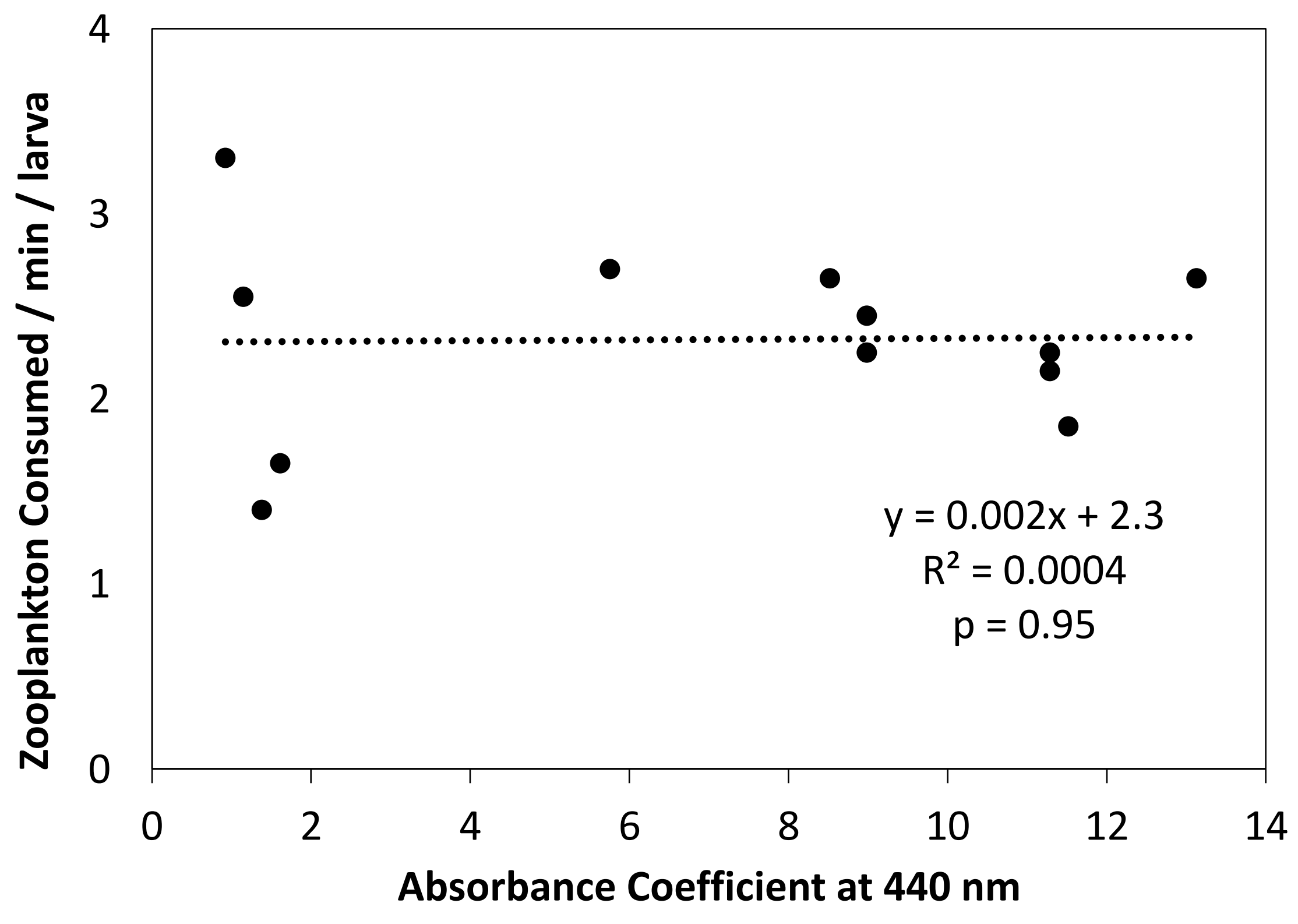




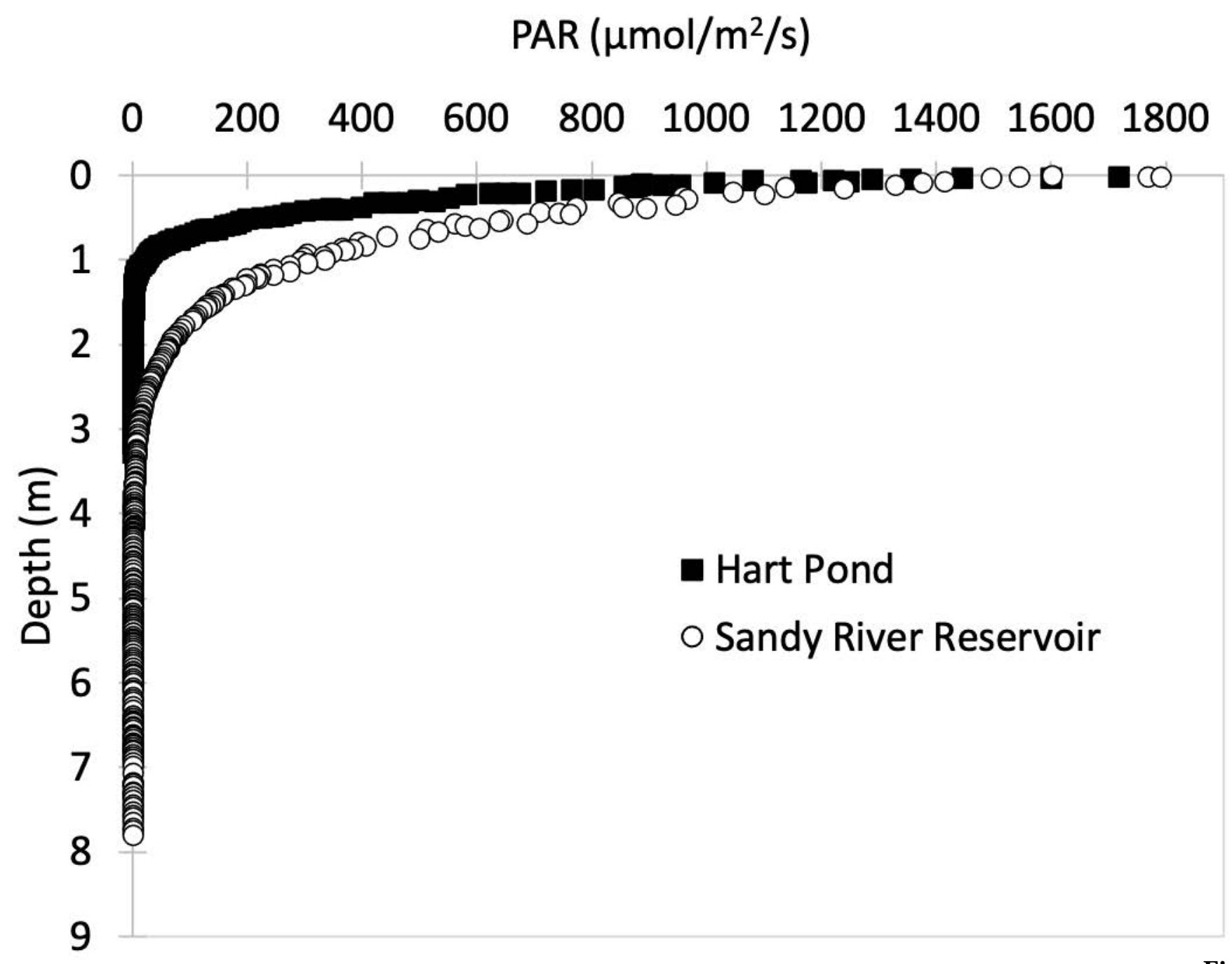


A

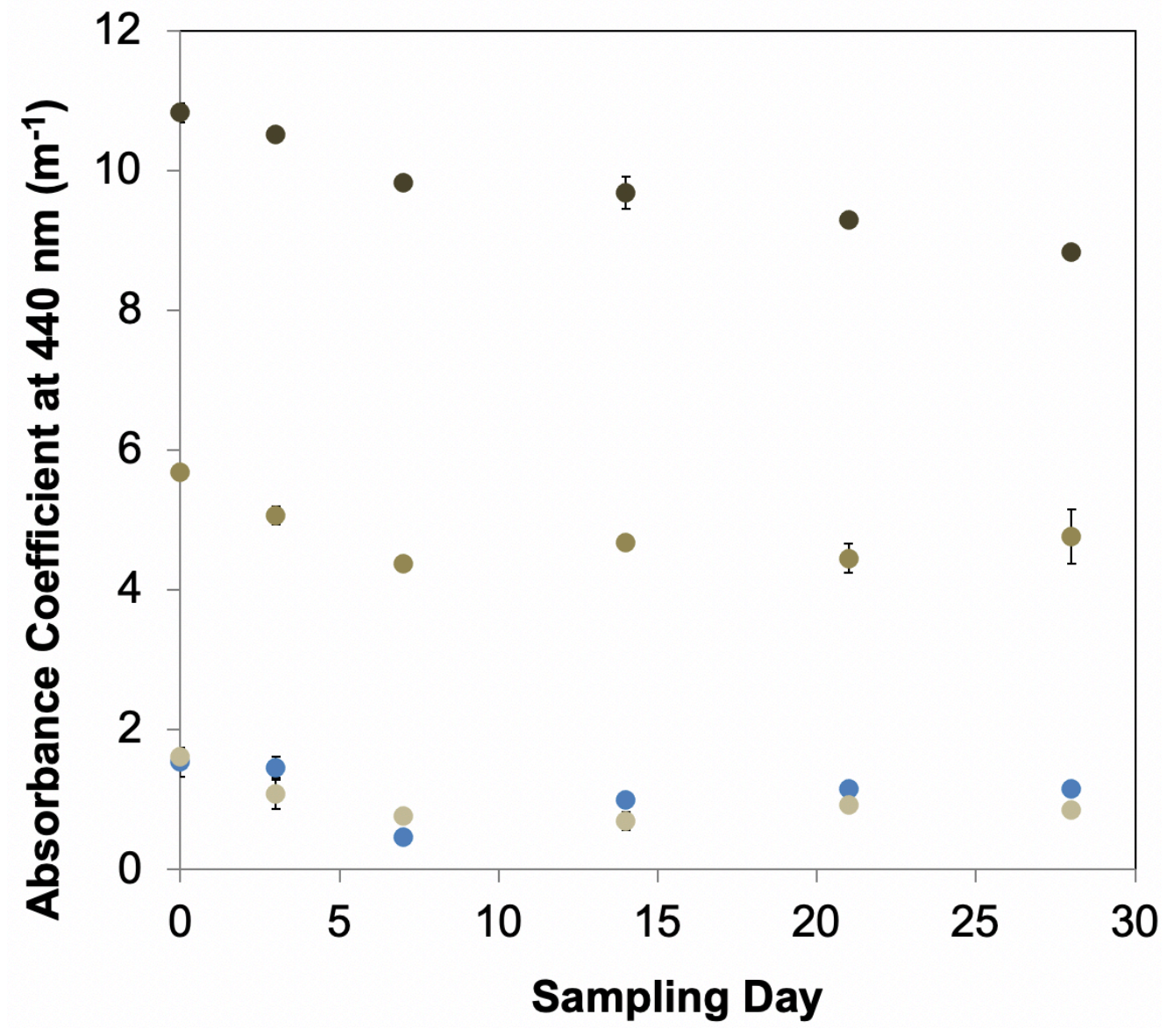

B

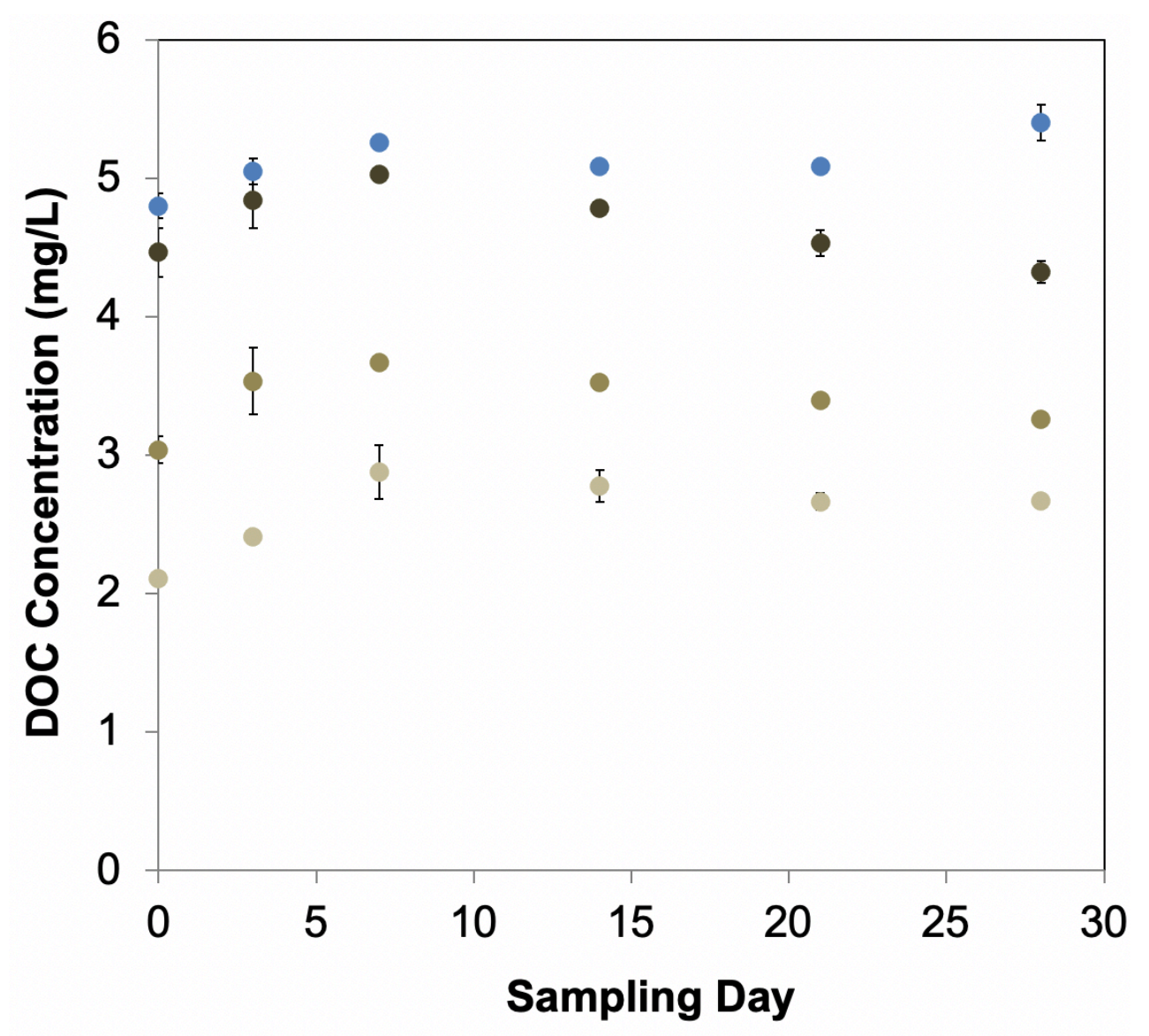

